\title{
Pathway Complexity in the Stacking of Imine-linked Macrocycles Related to Two-Dimensional Covalent Organic Frameworks
}

\author{
Shiwei Wang ${ }^{\star}$, Anton D. Chavez ${ }^{\dagger}$, Simil Thomas ${ }^{\ddagger}$, Hong Li ${ }^{\ddagger}$, \\ Nathan C. Flanders ${ }^{\dagger}$, Chao Sun ${ }^{\dagger \S}$, Michael J. Strauss ${ }^{\dagger}$, Lin X. Chen ${ }^{\dagger}$, \\ Albert J. Markvoort ${ }^{\perp}$, Jean-Luc Bredas ${ }^{\ddagger}$, , and William R. Dichtel ${ }^{\dagger, *}$ \\ ${ }^{\dagger}$ Department of Chemistry, Northwestern University, 2145 Sheridan Road, Evanston, Illinois \\ 60208, USA \\ $\$$ School of Chemistry and Biochemistry, Center for Organic Photonics and Electronics \\ (COPE), Georgia Institute of Technology, Atlanta, Georgia 30332-0400, USA \\ $\S$ Department of Chemistry and Chemical Biology, Baker Laboratory, Cornell University, \\ Ithaca, New York 14853, USA \\ "Chemical Sciences and Engineering Division, Argonne National Laboratory, Argonne, Illinois \\ 60439, USA. \\ ${ }^{\perp}$ Institute for Complex Molecular Systems and Computational Biology Group, Eindhoven \\ University of Technology, P.O. Box 513, 5600 MB Eindhoven, The Netherlands \\ Equal Contribution
}

\section{Supplementary Information}

\begin{tabular}{|c|}
\hline Correspondence Address \\
\hline Professor William R. Dichtel \\
Department of Chemistry \\
Northwestern University \\
2145 Sheridan Road \\
Evanston, IL 60208 (USA) \\
wdichtel@northwestern.edu \\
\hline
\end{tabular}

\section{Table of Contents}
A. Materials and Instrumentation
B. Computational Methodology
S-4
C. Synthetic Procedures
D. Additional Characterization
E. References 


\section{A. Materials and Instrumentation}

\section{Materials}

All reagents were purchased from commercial sources and used without further purification. Anhydrous toluene was obtained from a solvent purification system (JC Meyer System). Reactions were monitored by thin layer chromatography (TLC) carried out on EMD $250 \mu \mathrm{m}$ silica gel 60-F254 plates. Visualization was performed by UV light irradiation. Compounds S1, ${ }^{1}$ A-DAPB, ${ }^{1}$ (S)-3,7-dimethyloctyl 4-methylbenzenesulfonate ${ }^{2}$ and (R)-3,7dimethyloctyl 4-methylbenzenesulfonate ${ }^{2}$ were synthesized as previously reported.

\section{Instrumentation}

Nuclear magnetic resonance (NMR) spectra were recorded on a Bruker Advance III 500 MHz spectrometer using a CryoProbe 5mm DCH w/ Z-Gradient, on a $400 \mathrm{MHz}$ Agilent DD MR-400 spectrometer using an AutoX 5mm probe w/ Z-Gradient, or on a Bruker Avance III $600 \mathrm{MHz}$ spectrometer using a BBFO Smart Probe w/ Z-Gradient. All spectra were calibrated using residual solvent as an internal reference $\left(\mathrm{CDCl}_{3}: 7.26 \mathrm{ppm}\right.$ for ${ }^{1} \mathrm{H} \mathrm{NMR}, 77.00$ for ${ }^{13} \mathrm{C}$ NMR; Toluene-d $\mathrm{d}_{8}: 7.16$ for ${ }^{1} \mathrm{H}$ NMR; THF-d8: 3.58, 1.73 ppm for ${ }^{1} \mathrm{H}$ NMR)

Sonication was performed with a Branson 3510 ultrasonic cleaner with a power output of $100 \mathrm{~W}$ and a frequency of $40 \mathrm{kHz}$.

Matrix assisted laser desorption ionization time-of-flight (MALDI-TOF) mass spectra were recorded on a Bruker Autoflex III with a 2,5-dihydroxybenzoic acid matrix in reflectron positive mode.

Gel permeation chromatography (GPC) traces were recorded on an Agilent 1260 Infinity II system using 3 Agilent PLgel 300×7.5mm columns variable-wavelength diode array (254, 450, and $530 \mathrm{~nm}$ ) and refractive index detectors. All samples were dissolved in 
tetrahydrofuran $(1 \mathrm{mg} / \mathrm{mL})$ and sonicated for 10 minutes before being filtered through a 0.45 $\mu \mathrm{m}$ syringe filter (PTFE membrane).

Atomic force microscopy (AFM) was conducted using SPID Bruker FastScan AFM under the non-contact mode in air. Samples were drop-cast onto highly ordered pyrolytic graphite (HOPG) as the substrate and allowed to air-dry before imaging

Dynamic Light Scattering (DLS) data were collected using a Malvern Zetasizer Nano equipped with a $633 \mathrm{~nm}$ He-Ne $5 \mathrm{~mW}$ laser in a capped quartz cuvette with a $10 \mathrm{~mm}$ pathlength. Samples were filtered through a $5 \mu \mathrm{m}$ syringe filter (PTFE membrane). Sample measurements were optimized for each sample at room temperature and run in triplicate. The samples were then heated and held at the corresponding temperature for approximately 10 minutes before being measured using the same parameters. The data were analyzed using Malvern Zetasizer Series Software v7.11.

UV-Vis-NIR absorbance and turbidity spectra were recorded on a Cary 5000 UV-VisNIR spectrophotometer with a mercury lamp. Cuvette temperature and stirring were regulated with a Quantum Northwest Temperature Controller.

Circular dichroism (CD) measurements were taken on Jasco J-815 CD instrument. PDA and DMPDA macrocycle solutions were heated at $75^{\circ} \mathrm{C}$ for 15 minutes, cooled at room temperature ambiently before measurement at $20{ }^{\circ} \mathrm{C}$. Measurements are taken with standard sensitivity, D.I.T. at 1 second, band width at $1 \mathrm{~nm}$, data pitch at $1 \mathrm{~nm}$, from 600 to $300 \mathrm{~nm}$, and without accumulations.

Cooling curves were fit by performing a non-linear least square analysis using the method developed by Markvoort et al. ${ }^{3}$ and Eikelder et al. ${ }^{4}$ Accurate $T_{\mathrm{e}}$ values were obtained by applying a weight of 10 at $T_{\mathrm{e}}(\Delta \mathrm{T}=1)$. 


\section{B. Computational Methodology}

The geometry optimizations and single-point calculations on isolated macrocycles and macrocycle dimers were performed with the tuned long-range corrected $\omega$ B97X-D functional and the $6-31 \mathrm{G}(\mathrm{d}, \mathrm{p})$ basis set, using the Gaussian 09 Revision D.01 suite of programs. ${ }^{5}$ We note that, in the optimized geometry of single macrocycle, the six TAPB units form a co-planar structure. Initial geometry optimizations were carried out using the $\omega$ B97XD functional without tuning. Based on the optimized geometries, further geometry optimizations of the macrocycles were carried out at the tuned- $\omega$ B97XD level with the same basis set. The range-separation parameter $\omega$ was optimized following the IP tuning procedure ${ }^{6,7}$ for the molecular fragment shown below; the optimal $\omega$ value is $0.15 \mathrm{Bohr}^{-1}$.

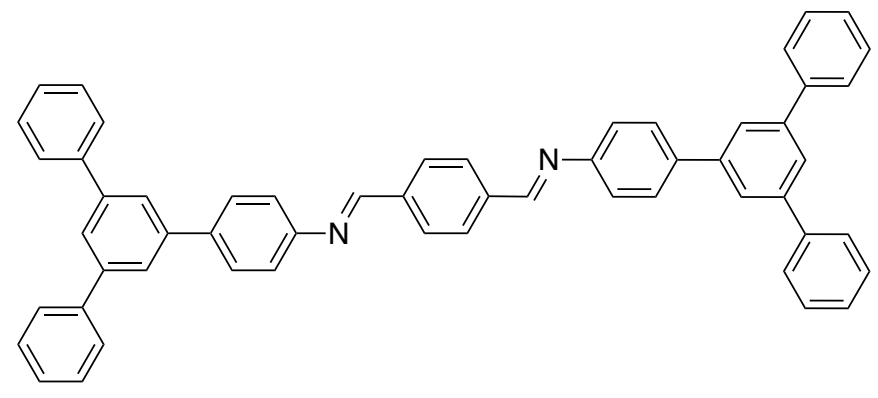




\section{Synthetic Procedures}

\section{General procedure for imine-linked macrocycle synthesis}

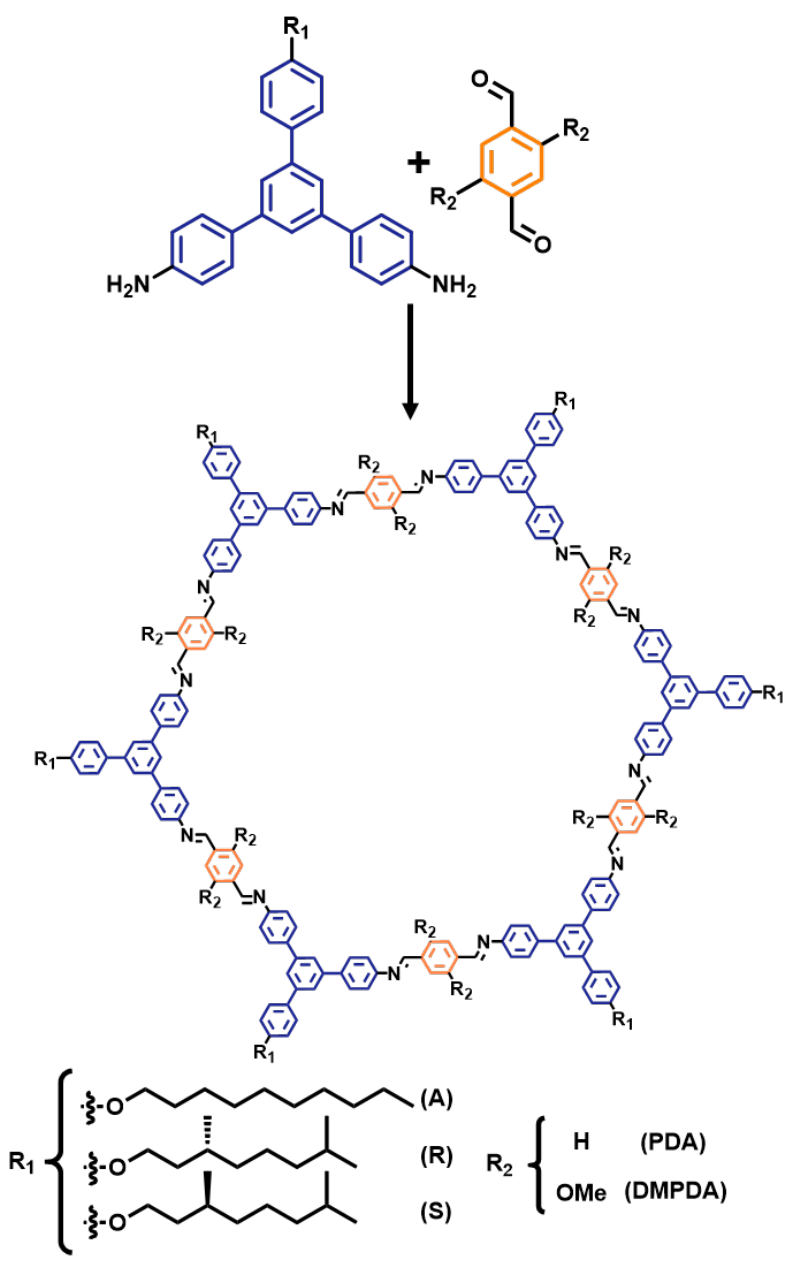

Scheme S1. Synthesis of achiral and chiral imine-linked macrocycles from the condensation of truncated TAPB analogues with either PDA or DMPDA.

Diamine (A-DAPB, S-DAPB, or R-DAPB, $0.05 \mathrm{~g}, 0.1 \mathrm{mmol}, 1.0$ equiv) and dialdehyde (PDA or DMPDA, 1.0 equiv) were dissolved in 1,4-dioxane (3.4 mL, ACS Reagent) to make a 30 $\mathrm{mM}$ solution of both components in a 4-mL closed vial (air-free not required), after which $\mathrm{CF}_{3} \mathrm{CO}_{2} \mathrm{H}$ (10 equiv for R/S-PDA, 0.5 equiv for all others) was added. A precipitate formed immediately after shaking. The solutions were left to sit without stirring for 1-6 days. The acid was neutralized by the addition of $\mathrm{Et}_{3} \mathrm{~N}$ (50 equiv for R/S-PDA, 10 equiv for all others). The 
precipitate was subsequently resuspended, rinsed, and centrifuged with $\mathrm{Et}_{2} \mathrm{O}(15 \mathrm{~mL} \times 3)$, EtOAc (15 mL x1), Hexane (15 mL x1), and anhydrous Acetone (15 mL x1). The solid was dried under vacuum at room temperature.

A-PDA: Performed on a $0.101 \mathrm{mmol}$ scale of A-DAPB. Reaction was run for 24 hours. Obtained $43.8 \mathrm{mg}$ ( $73 \%$ yield) of a yellow powder.

S-PDA: Performed on a $0.101 \mathrm{mmol}$ scale of S-DAPB. Reaction was run for 24 hours. Obtained $51.8 \mathrm{mg}(86 \%$ yield $)$ of a yellow powder.

R-PDA: Performed on a $0.101 \mathrm{mmol}$ scale of R-DAPB. Reaction was run for 24 hours. Obtained $52.4 \mathrm{mg}$ (87\% yield) of a yellow powder.

A-DMPDA: Performed on a $0.101 \mathrm{mmol}$ scale of A-DAPB. Reaction was run for 6 days (shorter reaction times revealed a population of five-membered MCs by MALDI-MS, which disappeared after extended reaction times). Obtained $43.7 \mathrm{mg}(66 \%$ yield) of an orange powder S-DMPDA: Performed on a $0.101 \mathrm{mmol}$ scale of S-DAPB. Reaction was run for 6 days (shorter reaction times revealed a population of five-membered MCs by MALDI-MS, which disappeared after extended reaction times). Obtained $37.5 \mathrm{mg}$ ( $56 \%$ yield) of an orange powder R-DMPDA: Performed on a $0.101 \mathrm{mmol}$ scale of R-DAPB. Reaction was run for 6 days (shorter reaction times revealed a population of five-membered MCs by MALDI-MS, which disappeared after extended reaction times). Obtained $39.0 \mathrm{mg}$ (59\% yield) of an orange powder. Preparation of macrocycle solutions for UV-Vis and CD spectroscopy: The macrocycle was dissolved in $100 \mathrm{~mL}$ dried toluene from JC Meyer solvent system through sonication and then combined with $100 \mathrm{~mL}$ 1,2-dichloroethane (DCE), which had been dried over activated 
molecular sieves. The solution was then diluted to the desired concentration by adding additional anhydrous DCE/toluene $(v / v=1: 1)$.

\section{Synthesis of poly-A-PDA}

A-DAPB $(0.030 \mathrm{~g}, 0.061 \mathrm{mmol})$ and PDA $(0.0082 \mathrm{~g}, 0.061 \mathrm{mmol}, 1$ equiv) were dissolved in ethyl acetate $(6 \mathrm{~mL}) .18 \mu \mathrm{L}$ of a $0.65 \mathrm{M}$ solution $\mathrm{CF}_{3} \mathrm{CO}_{2} \mathrm{H}$ in ethyl acetate $(0.012 \mathrm{mmol}, 0.2$ equiv) was then added. Immediately the solution turned yellow and precipitate formed shortly after. The solution sat for 3 min under ambient conditions before being neutralized by $10 \mu \mathrm{L}$ of $\mathrm{Et}_{3} \mathrm{~N}(0.72 \mathrm{mmol}, 1.2$ equiv). The precipitate was isolated by centrifugation and subsequently rinsed with $\mathrm{Et}_{2} \mathrm{O}(5 \mathrm{~mL} \times 3)$. The solid was dried under vacuum at room temperature, yielding poly-A-PDA as a yellow solid ( $15.6 \mathrm{mg}, 43 \%$ yield). 
Scheme S2. Synthesis of S2 and S3.
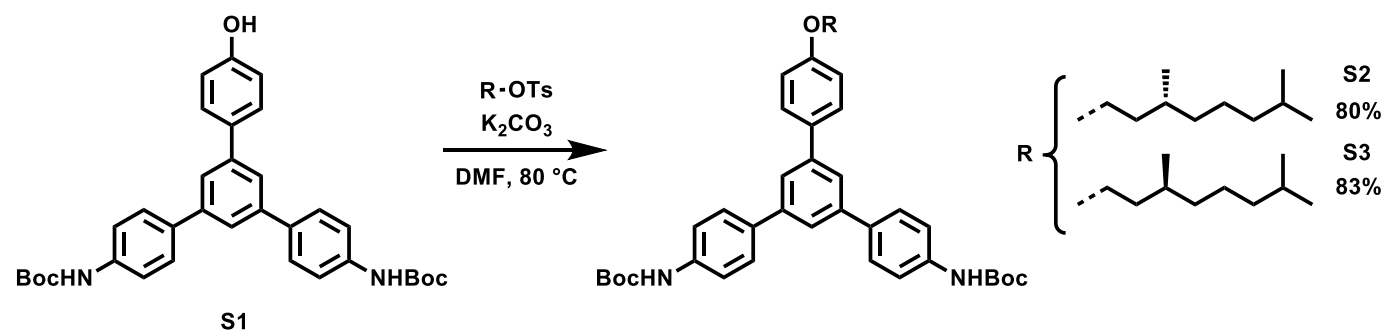

Synthesis of S2 and S3: S1, (R)-3,7-dimethyloctyl 4-methylbenzenesulfonate or (S)-3,7dimethyloctyl 4-methylbenzenesulfonate (2.5 equiv) and $\mathrm{K}_{2} \mathrm{CO}_{3}$ ( 2.5 equiv) were dissolved in DMF $(0.25 \mathrm{M}$ in $\mathbf{S 1})$ in a flame dried $20 \mathrm{~mL}$ reaction vial. The solution was sparged with $\mathrm{N}_{2}$ for $10 \mathrm{~min}$ before being heated at $100{ }^{\circ} \mathrm{C}$ for $4 \mathrm{~h}$. The solution was then poured into water $(50$ $\mathrm{mL})$ and extracted with $\mathrm{CH}_{2} \mathrm{Cl}_{2}(3 \times 20 \mathrm{~mL})$. The organic layers were combined, dried over anhydrous $\mathrm{MgSO}_{4}$ and concentrated by rotary evaporation. The crude material was purified by chromatography ( $\mathrm{SiO}_{2}, 25 \%$ v/v EtOAc:hexanes) yielding $\mathbf{S 2}$ and $\mathbf{S 3}$ as white fluffy powders.

S2: Done on $0.50 \mathrm{~g}(0.91 \mathrm{mmol})$ of S1, isolated $0.51 \mathrm{~g}$ (80\% yield).

S3: Done on $1.00 \mathrm{~g}(1.81 \mathrm{mmol})$ of $\mathbf{S 1}$, isolated $1.04 \mathrm{~g}$ (83\% yield).

${ }^{1} \mathrm{H}$ NMR (S2, $\left.500 \mathrm{MHz}, \mathrm{CDCl}_{3}\right) \delta 7.66(\mathrm{~m}, 3 \mathrm{H}), 7.61(\mathrm{~m}, 6 \mathrm{H}), 7.46(\mathrm{~d}, \mathrm{~J}=8.5 \mathrm{~Hz}, 4 \mathrm{H}), 7.00$ $(\mathrm{d}, \mathrm{J}=8.7 \mathrm{~Hz}, 2 \mathrm{H}), 6.55(\mathrm{~s}, 2 \mathrm{H}), 4.06(\mathrm{~m}, 2 \mathrm{H}), 1.86(\mathrm{~m}, 1 \mathrm{H}), 1.71(\mathrm{~m}, 1 \mathrm{H}), 1.63(\mathrm{~m}, 1 \mathrm{H}), 1.55$ (br, 19H), $1.33(\mathrm{~m}, 3 \mathrm{H}), 1.18(\mathrm{~m}, 3 \mathrm{H}), 0.97(\mathrm{~d}, \mathrm{~J}=6.6 \mathrm{~Hz}, 3 \mathrm{H}), 0.88(\mathrm{~d}, \mathrm{~J}=6.6 \mathrm{~Hz}, 6 \mathrm{H}) .{ }^{13} \mathrm{C}$ NMR (S2, $\left.126 \mathrm{MHz}, \mathrm{CDCl}_{3}\right) \delta 159.05,152.83,142.14,141.81,138.00,136.11,133.64,128.46$, $127.97,124.23,123.93,118.95,115.00,80.82,66.60,39.41,37.46,36.39,30.03,28.52,28.14$, $24.83,22.87,22.77,19.84$. 
${ }^{1} \mathrm{H}$ NMR (S3, $\left.500 \mathrm{MHz}, \mathrm{CDCl}_{3}\right) \delta 7.66(\mathrm{~m}, 3 \mathrm{H}), 7.61(\mathrm{~m}, 6 \mathrm{H}), 7.46(\mathrm{~d}, \mathrm{~J}=8.5 \mathrm{~Hz}, 4 \mathrm{H}), 7.00$ (d, J = 8.7 Hz, 2H), $6.53(\mathrm{~s}, 2 \mathrm{H}), 4.06(\mathrm{~m}, 2 \mathrm{H}), 1.86(\mathrm{~m}, 1 \mathrm{H}), 1.71(\mathrm{~m}, 1 \mathrm{H}), 1.62(\mathrm{~m}, 1 \mathrm{H}), 1.55$ (br, 19H), $1.35(\mathrm{~m}, 3 \mathrm{H}), 1.18(\mathrm{~m}, 3 \mathrm{H}), 0.96(\mathrm{~d}, \mathrm{~J}=6.6 \mathrm{~Hz}, 3 \mathrm{H}), 0.88(\mathrm{~d}, \mathrm{~J}=6.6 \mathrm{~Hz}, 6 \mathrm{H})$.

ESI HRMS $m / z$ calcd. for $\mathrm{C}_{44} \mathrm{H}_{56} \mathrm{~N}_{2} \mathrm{NaO}_{5}\left([\mathrm{M}+\mathrm{H}]^{+}\right)$693.4262, found 693.4226 . 
Scheme S3. Synthesis of R-DAPB and S-DAPB.
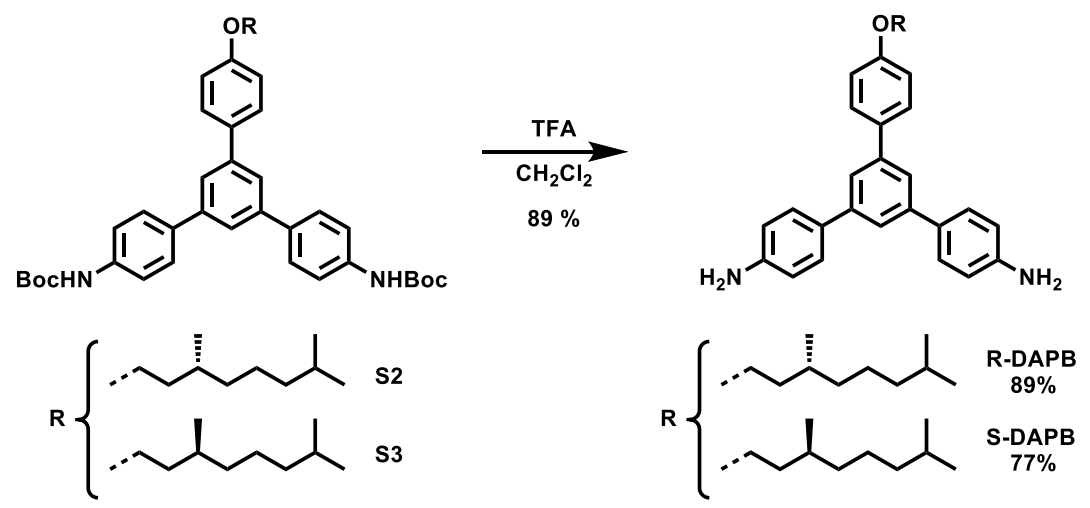

Synthesis of S-DAPB and R-DAPB: S2 or S3 was dissolved in $\mathrm{CH}_{2} \mathrm{Cl}_{2}(0.16 \mathrm{M})$ in a $20 \mathrm{~mL}$ reaction vial, followed by the slow addition of $\mathrm{CF}_{3} \mathrm{CO}_{2} \mathrm{H}$ (20 equiv, dropwise). The solution was then stirred for $1 \mathrm{~h}$, during which gas evolved out of the solution. The solution was then poured into a saturated $\mathrm{NaHCO}_{3}$ solution $(30 \mathrm{~mL})$ and extracted with $\mathrm{CH}_{2} \mathrm{Cl}_{2}(3 \times 15 \mathrm{~mL})$. The organic layers were combined and washed with $1 \mathrm{M} \mathrm{KOH}(3 \times 15 \mathrm{~mL})$. The organic solution was dried over anhydrous $\mathrm{MgSO}_{4}$ and concentrated by rotary evaporation, yielding pure $\mathbf{R}-$ DAPB and S-DAPB as white powders.

R-DAPB: Done on $0.49 \mathrm{~g}(0.71 \mathrm{mmol})$ of $\mathbf{S 2}$, isolated $0.31 \mathrm{~g}(89 \%$ yield $)$.

S-DAPB: Done on $1.00 \mathrm{~g}(1.44 \mathrm{mmol})$ of S3, isolated $0.54 \mathrm{~g}$ (77\% yield).

${ }^{1} \mathrm{H}$ NMR (R-DAPB, $\left.500 \mathrm{MHz}, \mathrm{CDCl}_{3}\right) \delta 7.63(\mathrm{~m}, 5 \mathrm{H}), 7.53(\mathrm{~d}, \mathrm{~J}=8.5 \mathrm{~Hz}, 4 \mathrm{H}), 7.01(\mathrm{~d}, \mathrm{~J}=$ $8.8 \mathrm{~Hz}, 2 \mathrm{H}), 6.79(\mathrm{~d}, \mathrm{~J}=8.6 \mathrm{~Hz}, 4 \mathrm{H}), 4.07(\mathrm{~m}, 2 \mathrm{H}), 3.74(\mathrm{br}, 4 \mathrm{H}), 1.87(\mathrm{~m}, 1 \mathrm{H}), 1.72(\mathrm{~m}, 1 \mathrm{H})$, $1.64(\mathrm{~m}, 1 \mathrm{H}), 1.57(\mathrm{~m}, 1 \mathrm{H}), 1.34(\mathrm{~m}, 3 \mathrm{H}), 1.20(\mathrm{~m}, 3 \mathrm{H}), 0.98(\mathrm{~d}, \mathrm{~J}=6.6 \mathrm{~Hz}, 3 \mathrm{H}), 0.90(\mathrm{~d}, \mathrm{~J}=$ 6.6 Hz, 6H). ${ }^{13} \mathrm{C}$ NMR (R-DAPB, $\left.126 \mathrm{MHz}, \mathrm{CDCl} 3\right) \delta$ 158.88, 146.07, 142.16, 141.85, 133.99, $131.88,128.41,128.32,123.30,123.29,115.50,114.90,66.56,39.39,37.45,36.38,30.01$, $28.12,24.81,22.86,22.76,19.83$. 
${ }^{1} \mathrm{H}$ NMR (S-DAPB, $\left.500 \mathrm{MHz}, \mathrm{CDCl}_{3}\right) \delta 7.64(\mathrm{~m}, 5 \mathrm{H}), 7.53(\mathrm{~d}, \mathrm{~J}=8.5 \mathrm{~Hz}, 4 \mathrm{H}), 7.01(\mathrm{~d}, \mathrm{~J}=8.8$ Hz, 2H), $6.79(\mathrm{~d}, \mathrm{~J}=8.6 \mathrm{~Hz}, 4 \mathrm{H}), 4.07(\mathrm{~m}, 2 \mathrm{H}), 3.73(\mathrm{br}, 4 \mathrm{H}), 1.87(\mathrm{~m}, 1 \mathrm{H}), 1.73(\mathrm{~m}, 1 \mathrm{H}), 1.64$ (m, 1H), $1.57(\mathrm{~m}, 1 \mathrm{H}), 1.34(\mathrm{~m}, 3 \mathrm{H}), 1.20(\mathrm{~m}, 3 \mathrm{H}), 0.99(\mathrm{~d}, \mathrm{~J}=6.6 \mathrm{~Hz}, 3 \mathrm{H}), 0.91(\mathrm{~d}, \mathrm{~J}=6.6 \mathrm{~Hz}$, 6H). ${ }^{13} \mathrm{C}$ NMR (S-DAPB, $\left.126 \mathrm{MHz}, \mathrm{CDCl} 3\right) \delta$ 158.88, 146.07, 142.16, 141.84, 133.99, 131.87, $128.41,128.32,123.28,123.28,115.50,114.90,66.55,39.39,37.44,36.38,30.01,28.11,24.80$, $22.86,22.75,19.82$.

ESI HRMS $m / z$ calcd. for $\mathrm{C}_{34} \mathrm{H}_{41} \mathrm{~N}_{2} \mathrm{O}\left([\mathrm{M}+\mathrm{H}]^{+}\right) 493.3213$, found 493.3207 . 


\section{Additional Characterization}

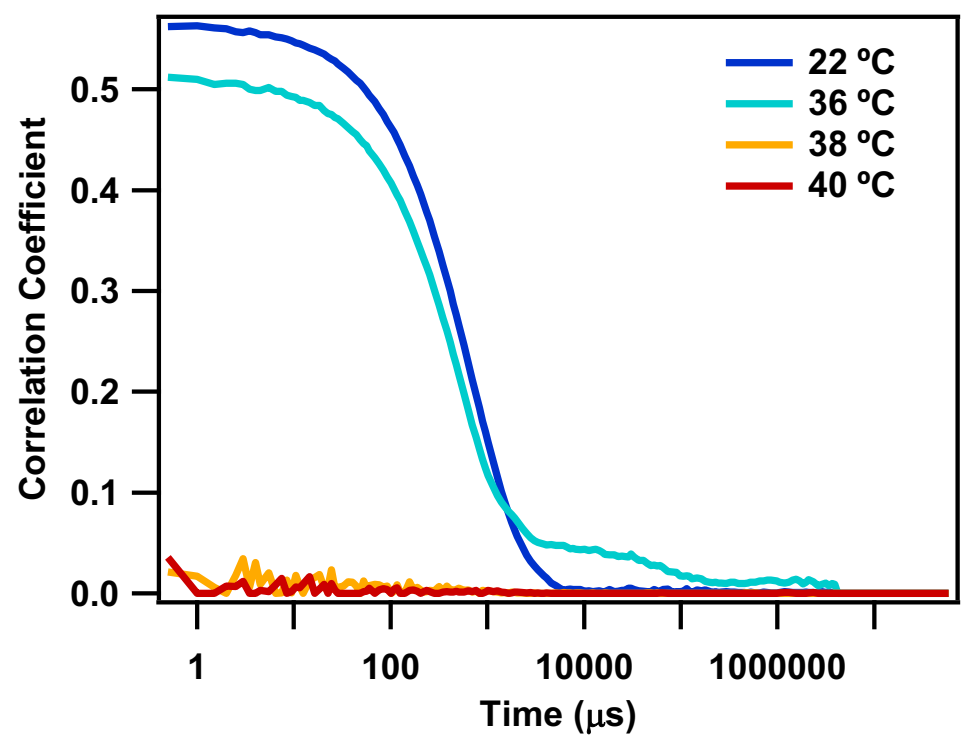

Figure S1. DLS correlograms of S-DMPDA $(0.011 \mathrm{mg} / \mathrm{mL}$ in DCE:toluene, $v: v=1: 1)$ at various temperatures. The lack of correlograms at 38 and $40{ }^{\circ} \mathrm{C}$ suggests molecularly dissolved macrocycles. 


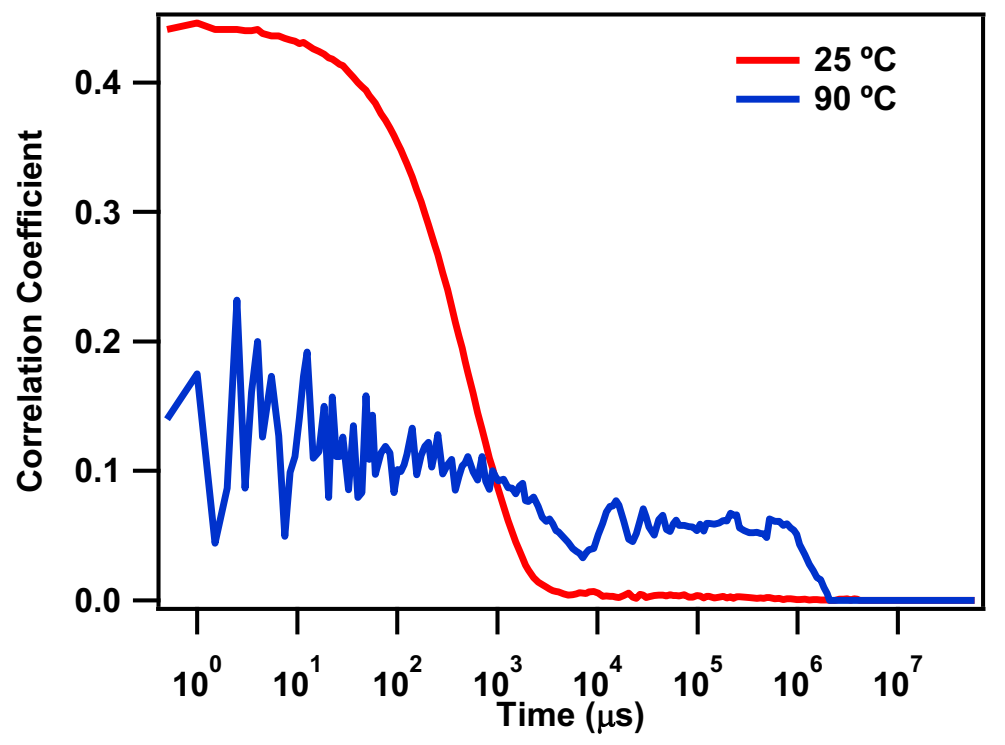

Figure S2. DLS correlograms of A-PDA $\left(0.01 \mathrm{mg} / \mathrm{mL}\right.$ in Toluene) at either $25^{\circ} \mathrm{C}$ or $90{ }^{\circ} \mathrm{C}$, suggesting no aggregation at higher temperatures.

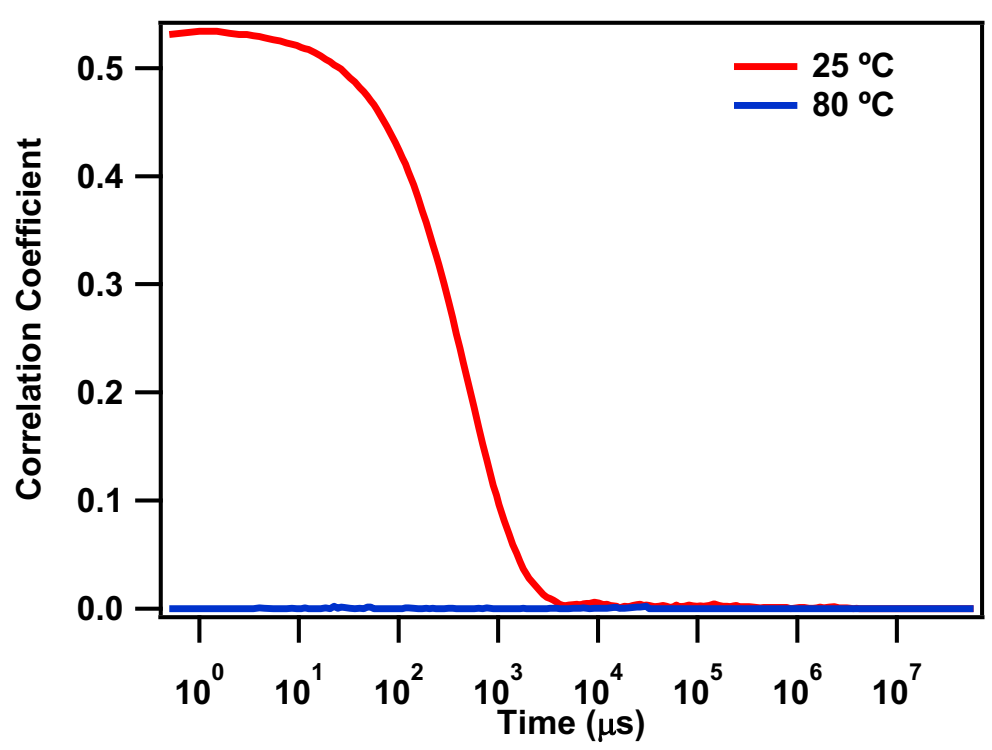

Figure S3. DLS correlograms of A-DMPDA $\left(0.011 \mathrm{mg} / \mathrm{mL}\right.$ in Toluene) at either $25^{\circ} \mathrm{C}$ or 80 ${ }^{\circ} \mathrm{C}$, suggesting no aggregation at higher temperatures. 


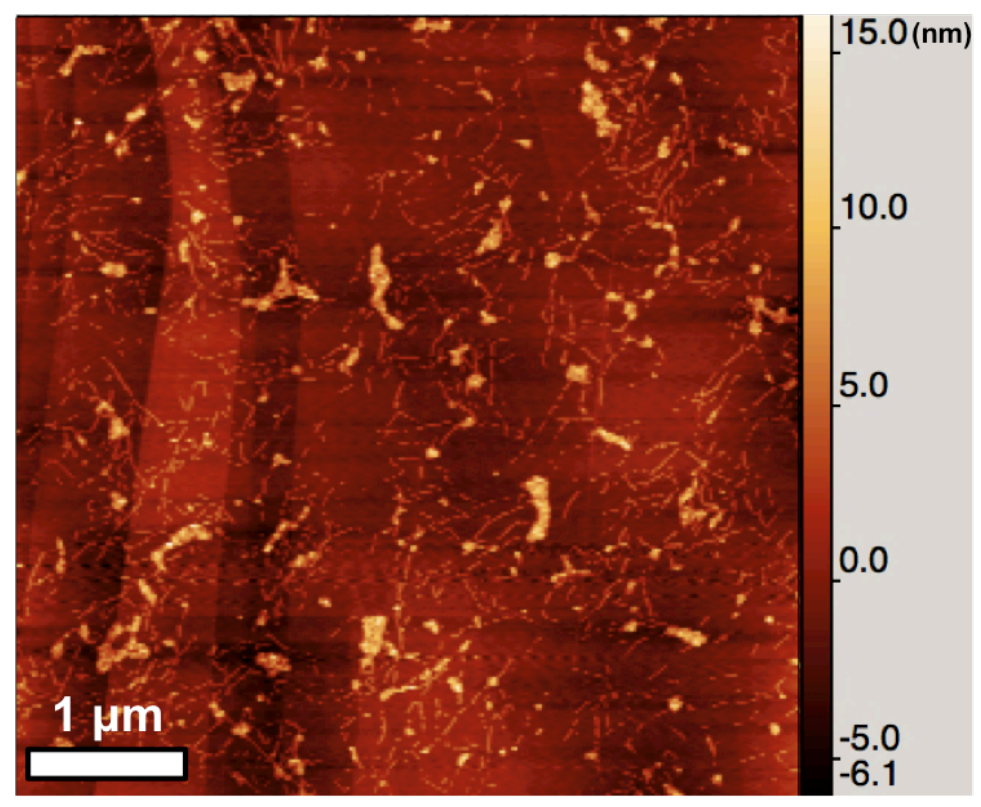

Figure S4. A-DMPDA macrocycle solid was dissolved in solution $(0.01 \mathrm{mg} / \mathrm{mL}$ in toluene $)$ without heating and drop casted on HOPG.

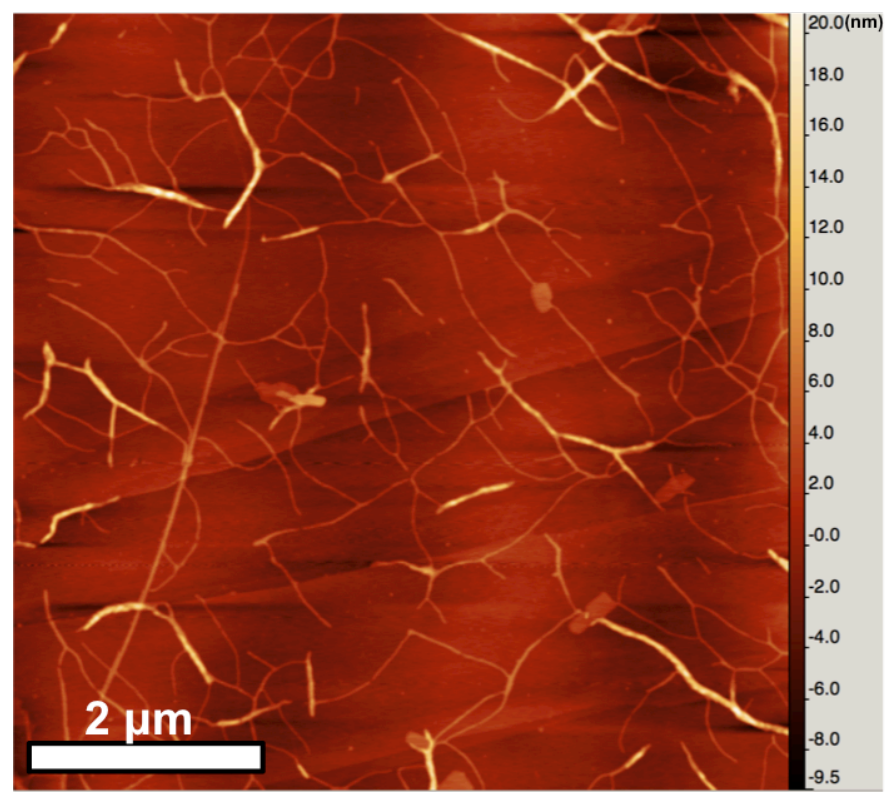

Figure S5. Solution of A-DMPDA $\left(0.01 \mathrm{mg} / \mathrm{mL}\right.$ in toluene) was heated to $85{ }^{\circ} \mathrm{C}$, cooled to room temperature, and drop casted on HOPG. 
A

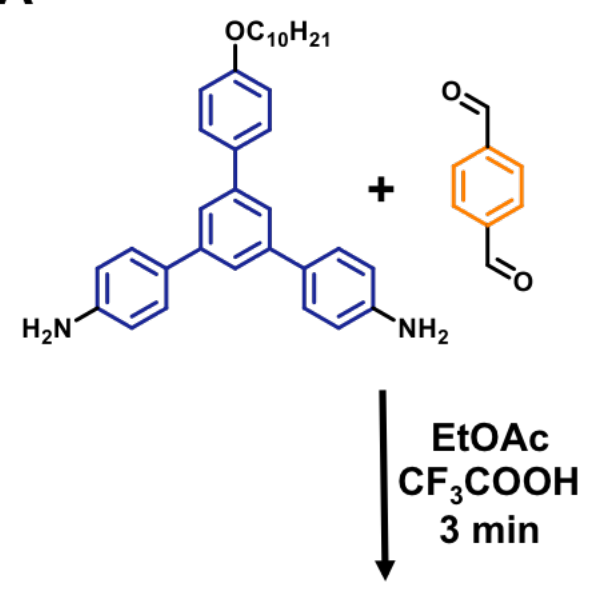

B

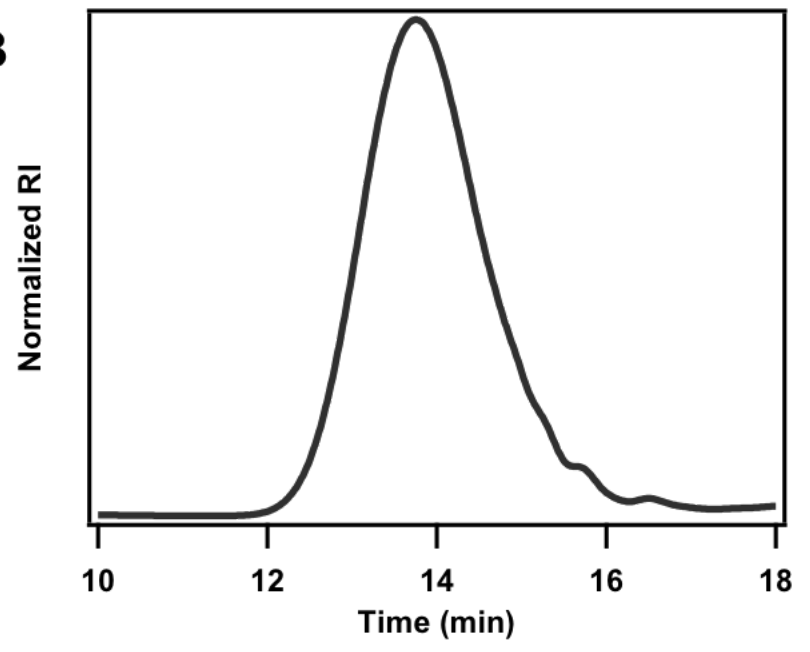

$\mathbf{C}_{0.6}$

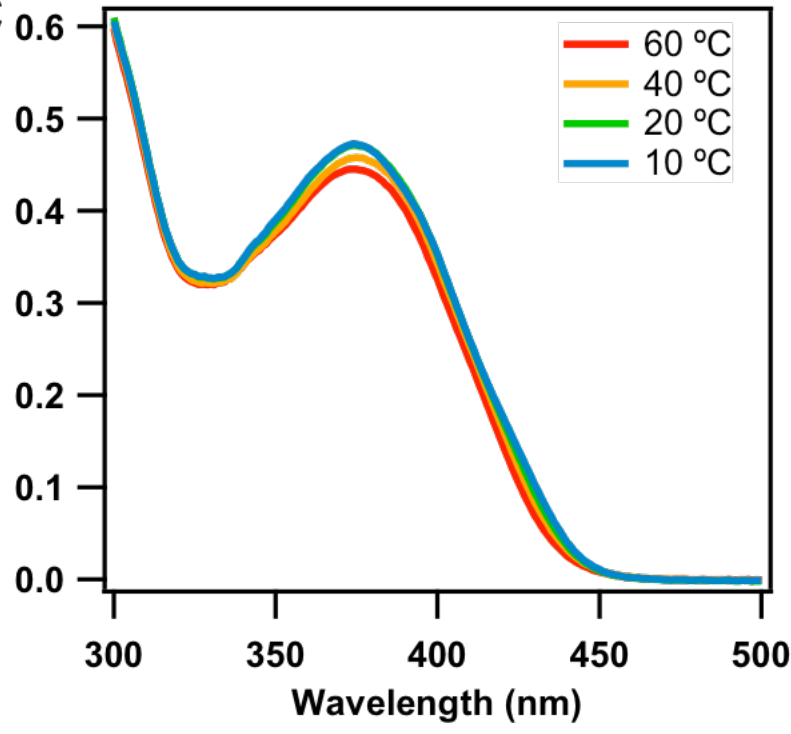

Figure S6. (A) Reaction scheme for the formation of poly-A-PDA. (B) GPC trace of poly-APDA, showing a broad polymer distribution. (C) UV-Vis of poly-A-PDA $(0.01 \mathrm{mg} / \mathrm{mL}$ in $1: 1$ $v / v$ DCE:toluene) at various temperatures, showing little change upon heating. 


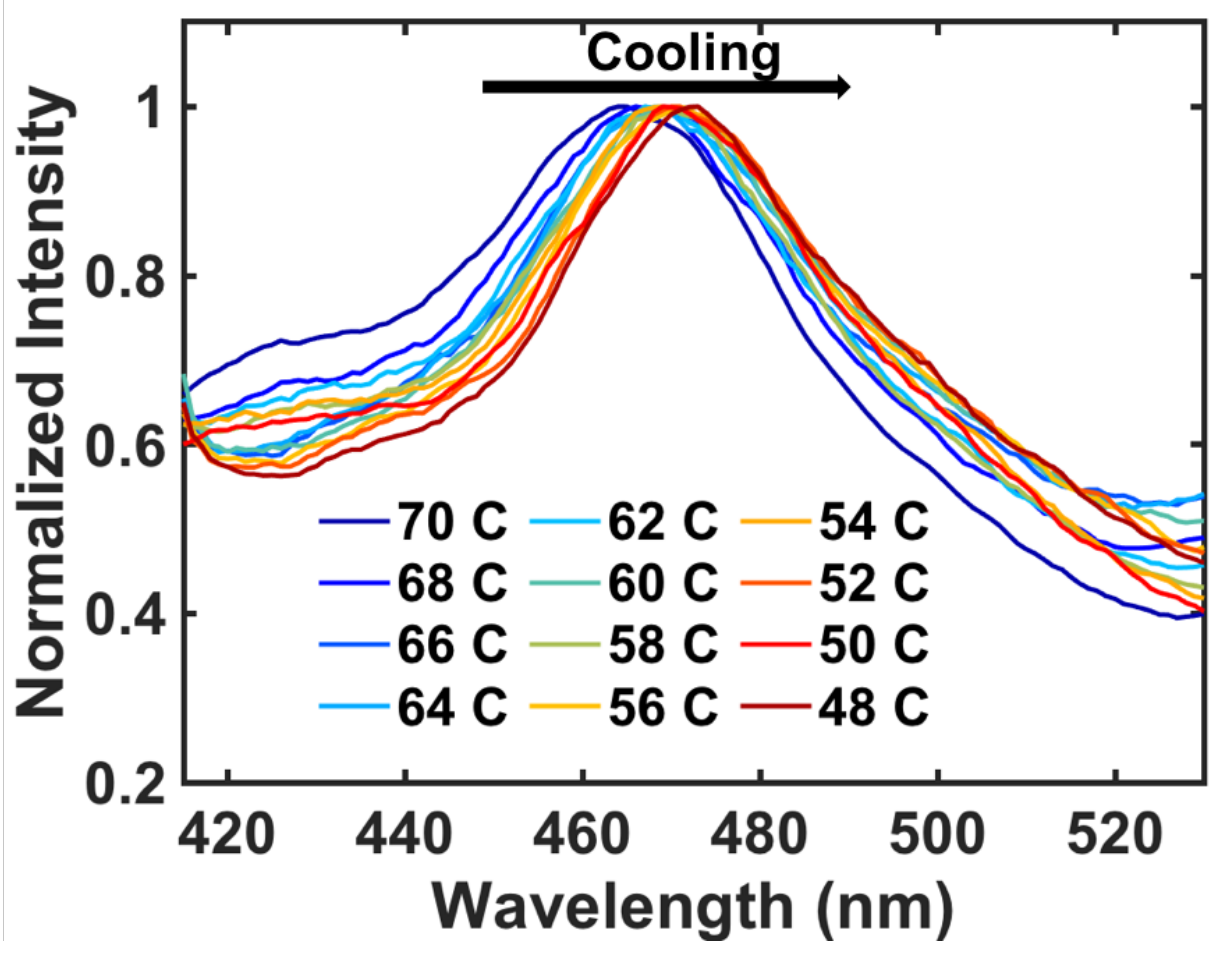

Figure S7. Normalized fluorescent spectra of A-PDA solution $(0.02 \mathrm{mg} / \mathrm{mL}$ in $1: 1 \quad v / v$ DCE:toluene) upon cooling from $70{ }^{\circ} \mathrm{C}$ (blue) to $48{ }^{\circ} \mathrm{C}$ (red) at $0.1{ }^{\circ} \mathrm{C} / \mathrm{min}$. 

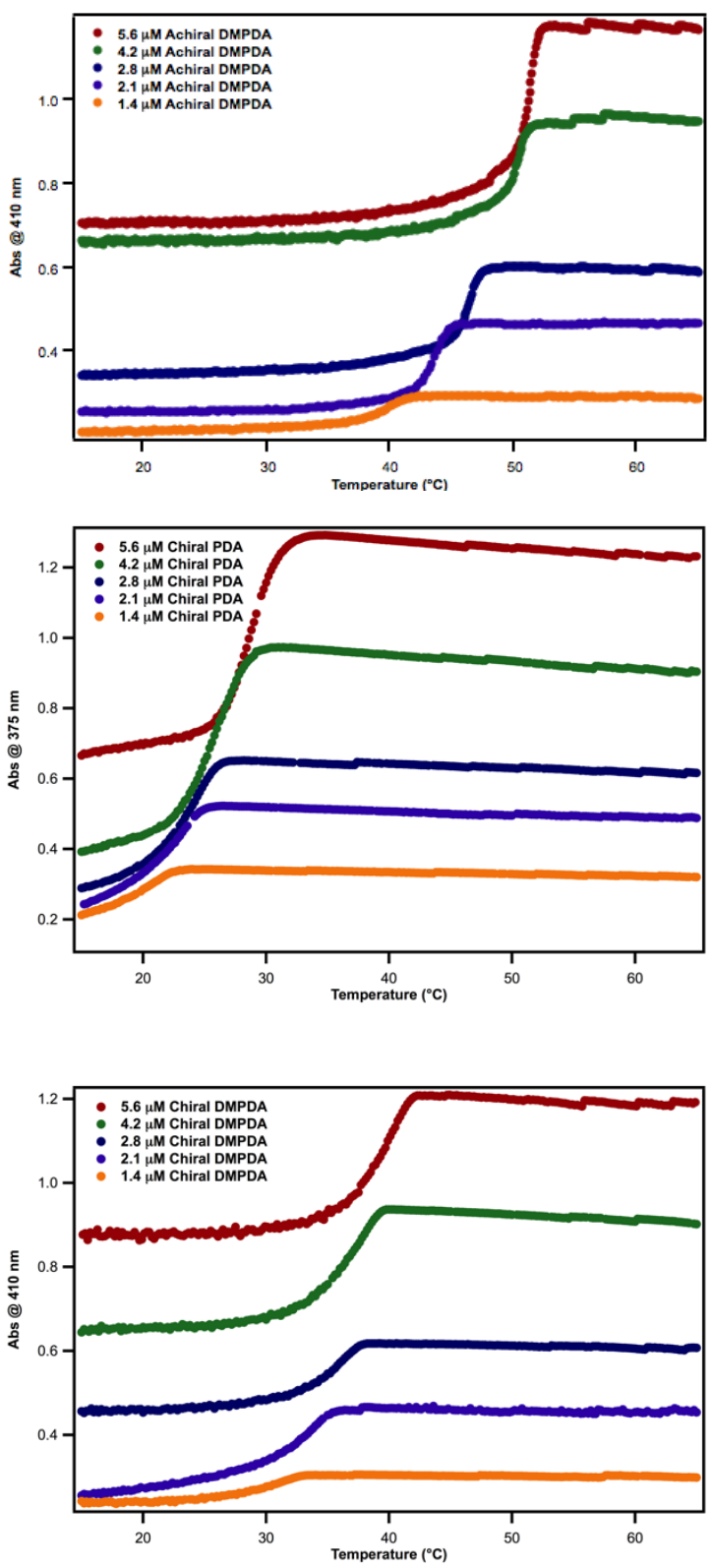

Figure S8. UV-vis cooling curves of A-DMPDA, S-PDA, and R-DMPDA (1:1 v/v DCE: touluene) cooled at $0.1{ }^{\circ} \mathrm{C} / \mathrm{min}$ at various concentrations, monitored at $\lambda$ max $=375 \mathrm{~nm}$ (PDA) or $410 \mathrm{~nm}$ (DMPDA). 

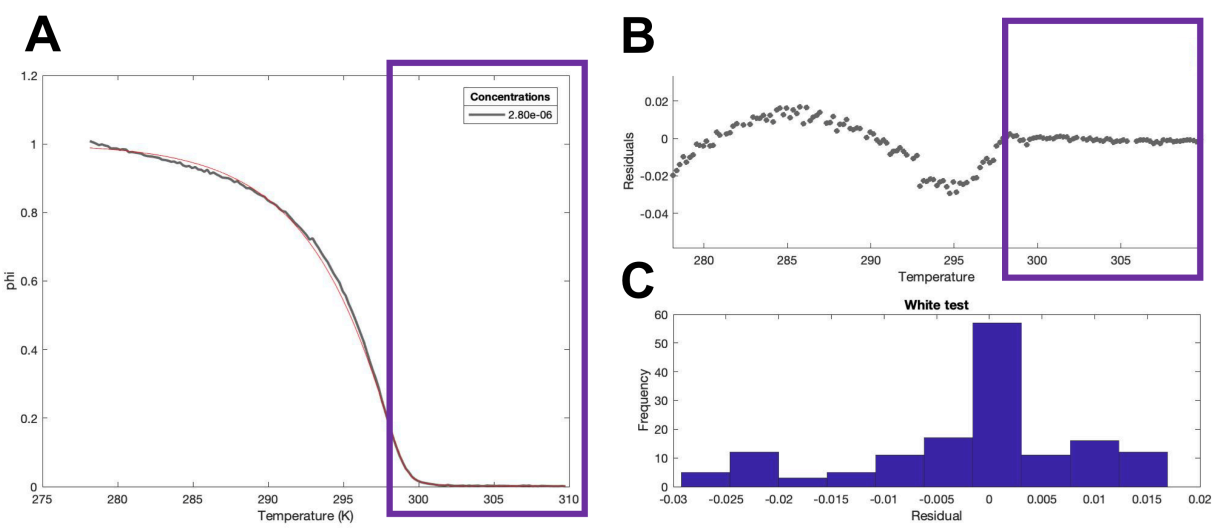

Figure S9. (A) Cooling curve of S-PDA ( $2.8 \mu \mathrm{M}$ in 1:1 $v / v$ DCE:toluene) and fit curve between $310 \mathrm{~K}$ and $280 \mathrm{~K}$. (B) Residual analysis of the cooling curve and fit curve. No significant residual was observed around $T_{\mathrm{e}}$. (C) White test of the cooling curve and fit curve.

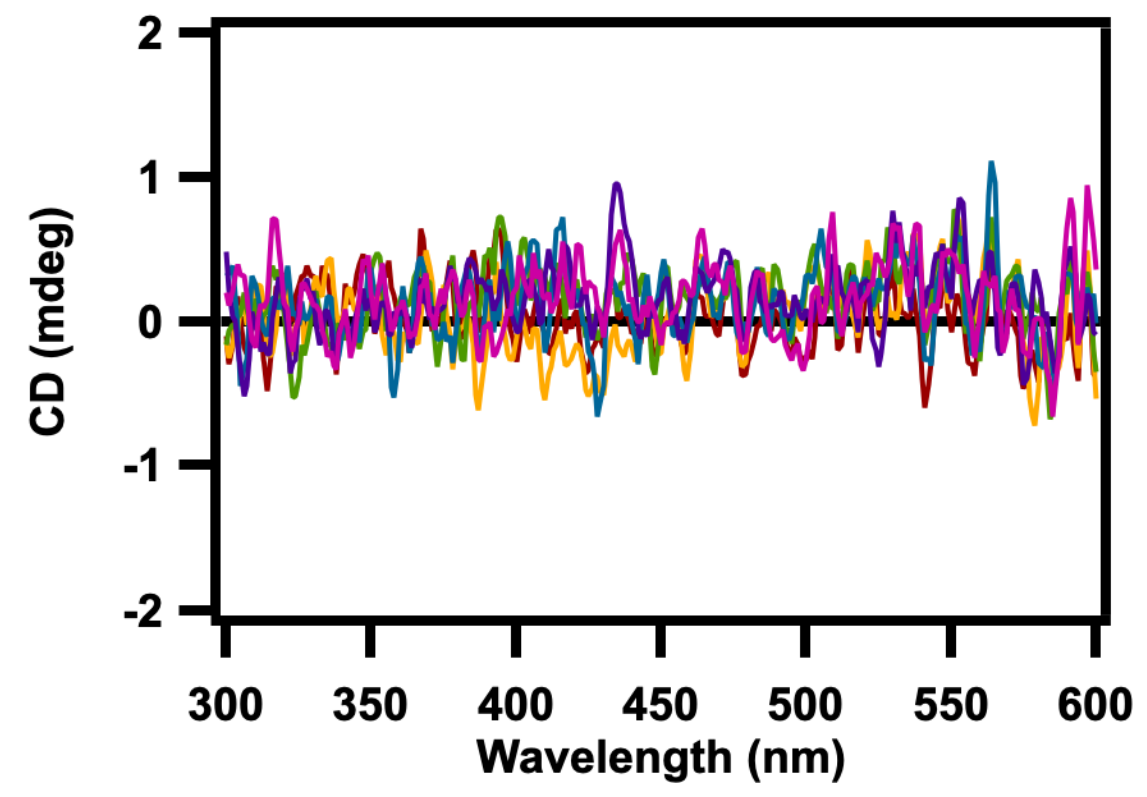

Figure S10. CD spectra of A-PDA, A-DMPDA, S-PDA, S-DMPDA, R-PDA, R-DMPDA solution $(2.8 \mu \mathrm{M}$ in $1: 1 v / v$ DCE:toluene $)$ at $75^{\circ} \mathrm{C}$. 

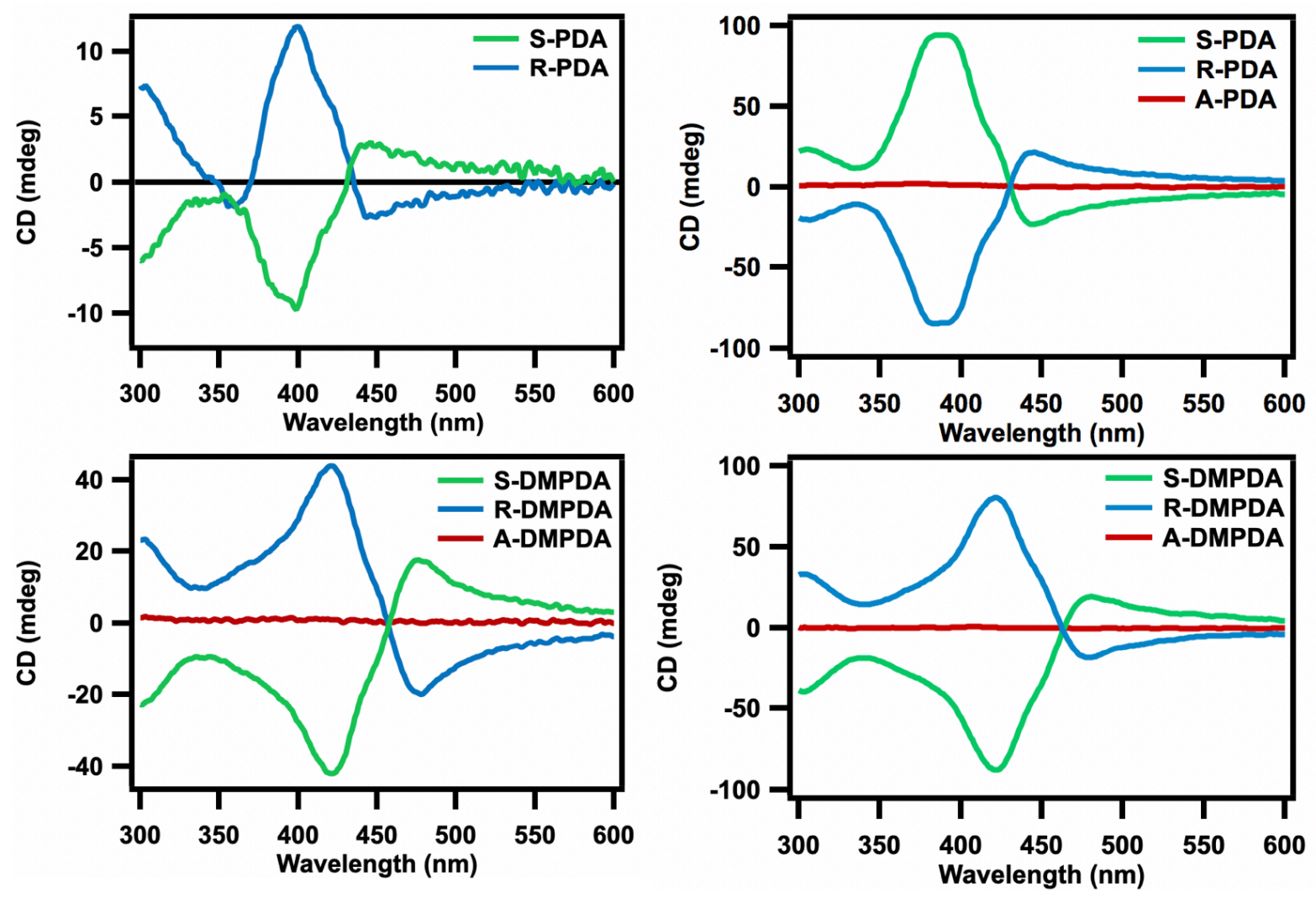

Figure S11. CD spectra of PDA macrocycle solutions $(2.8 \mu \mathrm{M}$ in 1:1 DCE:toluene) after cooling to $20{ }^{\circ} \mathrm{C}$ and standing for 5 minutes (Upper Left) and for 3 hours (Upper Right, Same as Figure 4A). CD spectra of DMPDA macrocycle solutions $(2.8 \mu \mathrm{M}$ in 1:1 DCE:toluene) after cooling to $20{ }^{\circ} \mathrm{C}$ and standing for 5 minutes (Lower Left) and for 3 hours (Lower Right, Same as Figure 4B). 


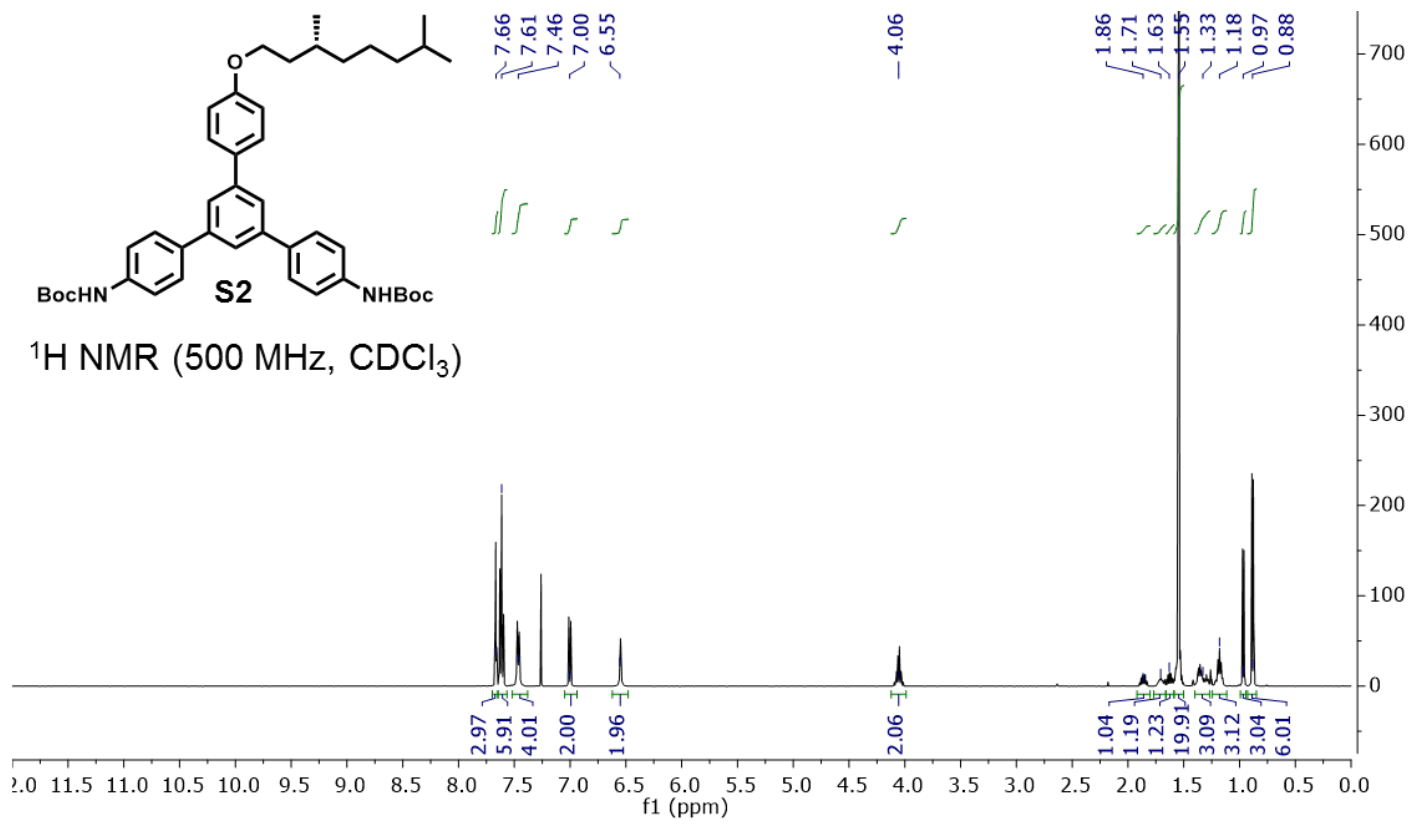

Figure S12. ${ }^{1} \mathrm{H}$ NMR spectrum $\left(\mathrm{CDCl}_{3}, 500 \mathrm{MHz}, 298 \mathrm{~K}\right)$ of $\mathbf{S 2}$.

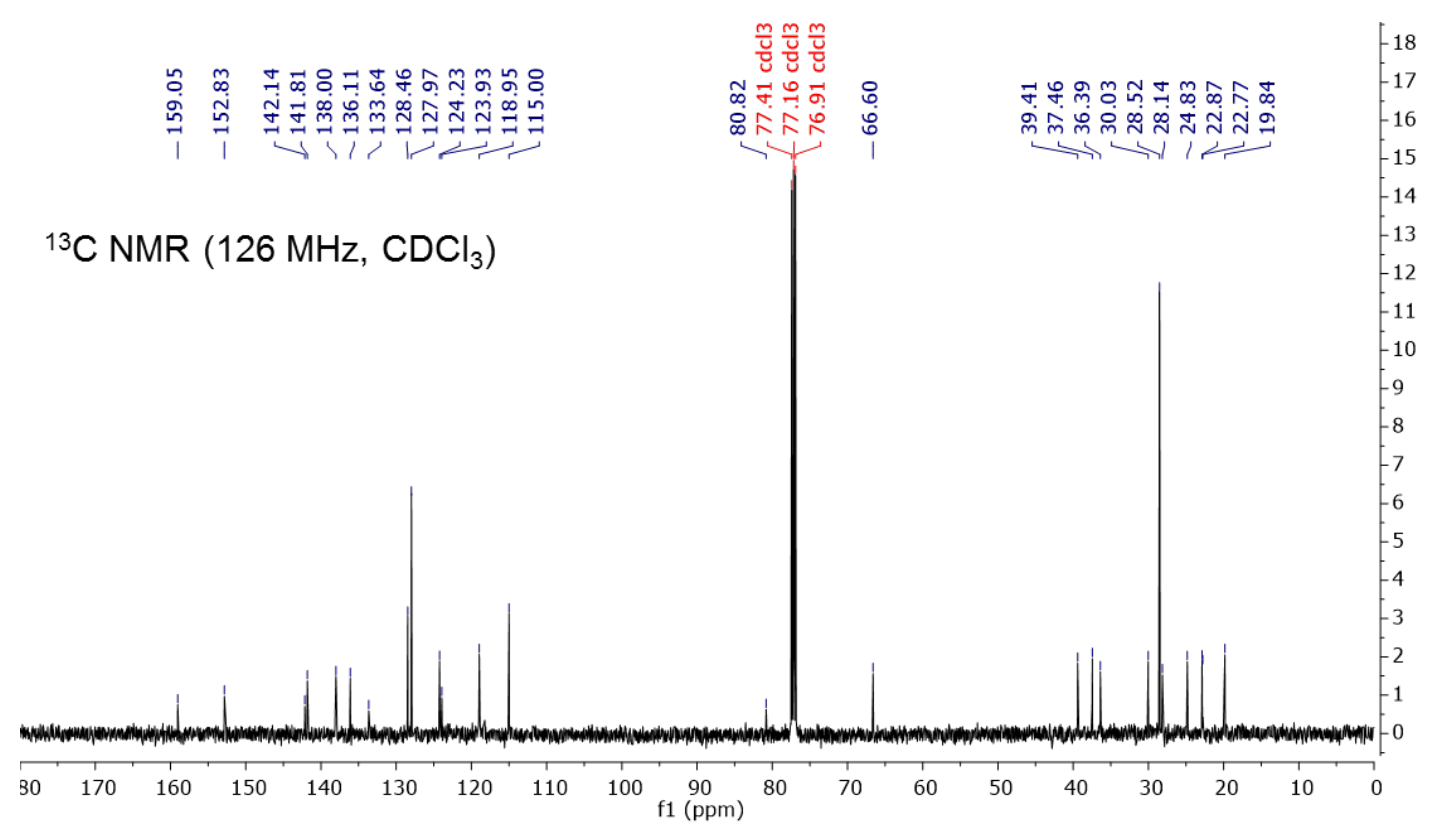

Figure S13. ${ }^{13} \mathrm{C}$ NMR spectrum $\left(\mathrm{CDCl}_{3}, 126 \mathrm{MHz}, 298 \mathrm{~K}\right)$ of $\mathbf{S 2}$. 


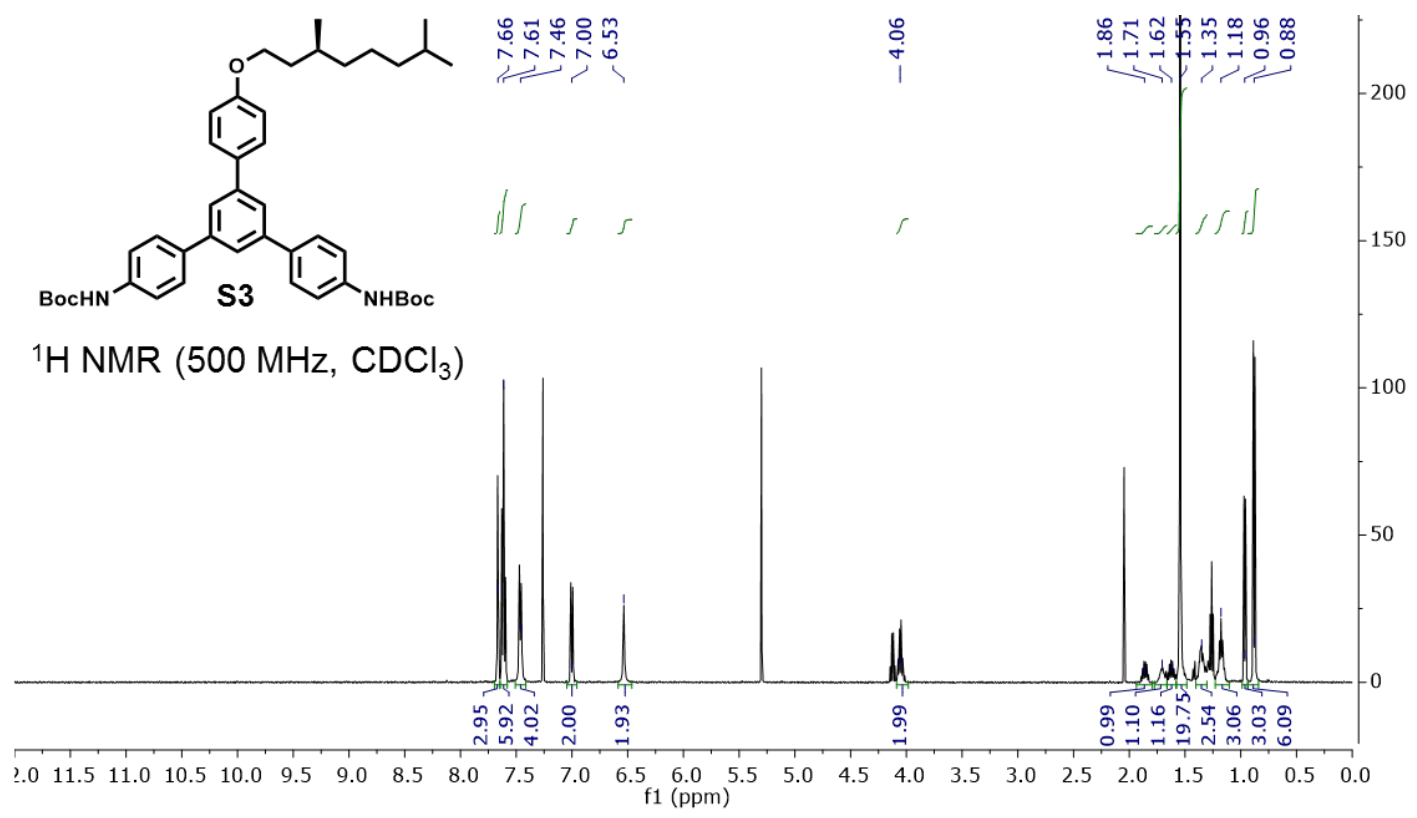

Figure S14. ${ }^{1} \mathrm{H}$ NMR spectrum $\left(\mathrm{CDCl}_{3}, 500 \mathrm{MHz}, 298 \mathrm{~K}\right)$ of $\mathbf{S 3}$.

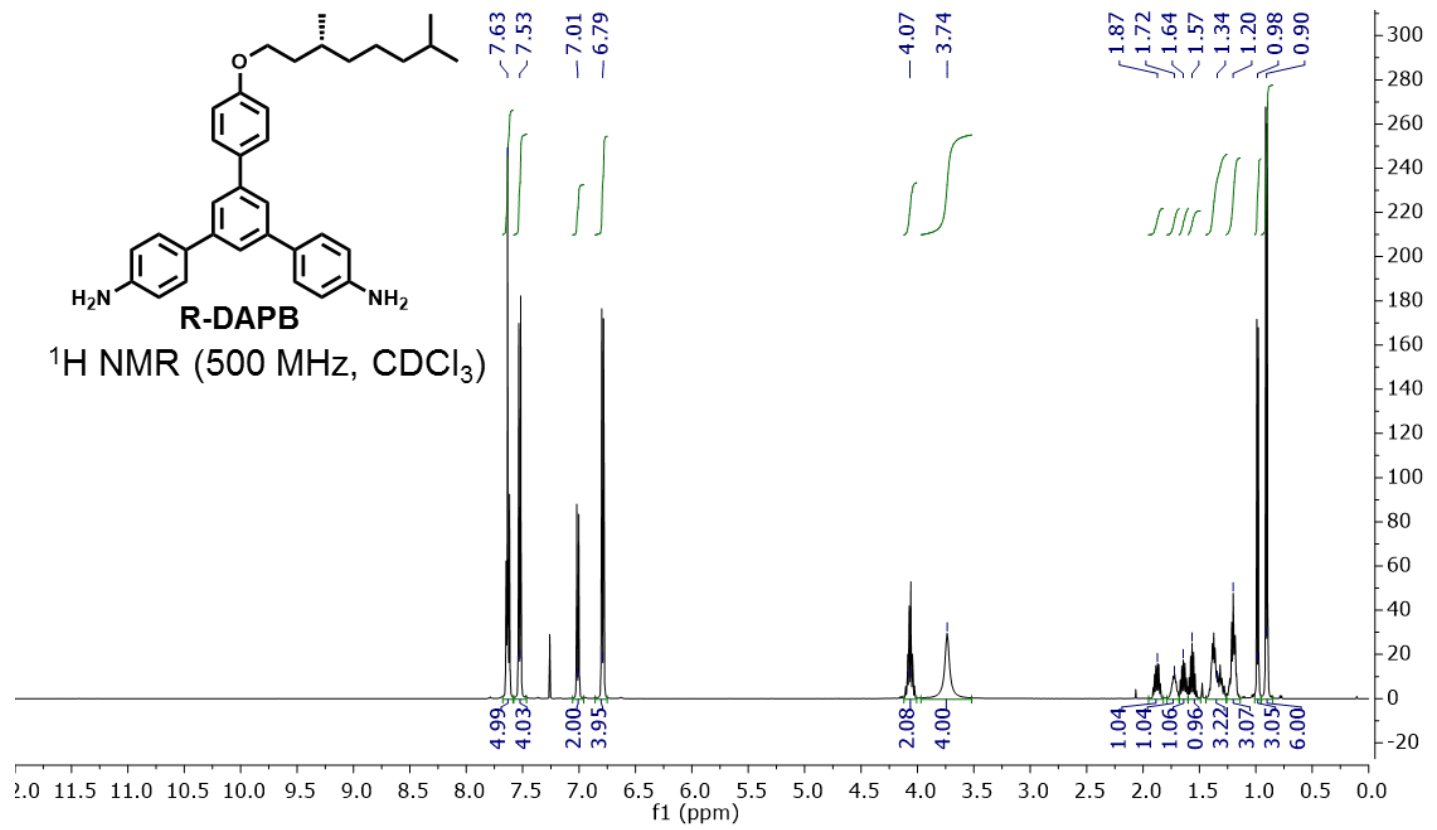

Figure S15. ${ }^{1} \mathrm{H}$ NMR spectrum $\left(\mathrm{CDCl}_{3}, 500 \mathrm{MHz}, 298 \mathrm{~K}\right)$ of R-DAPB. 


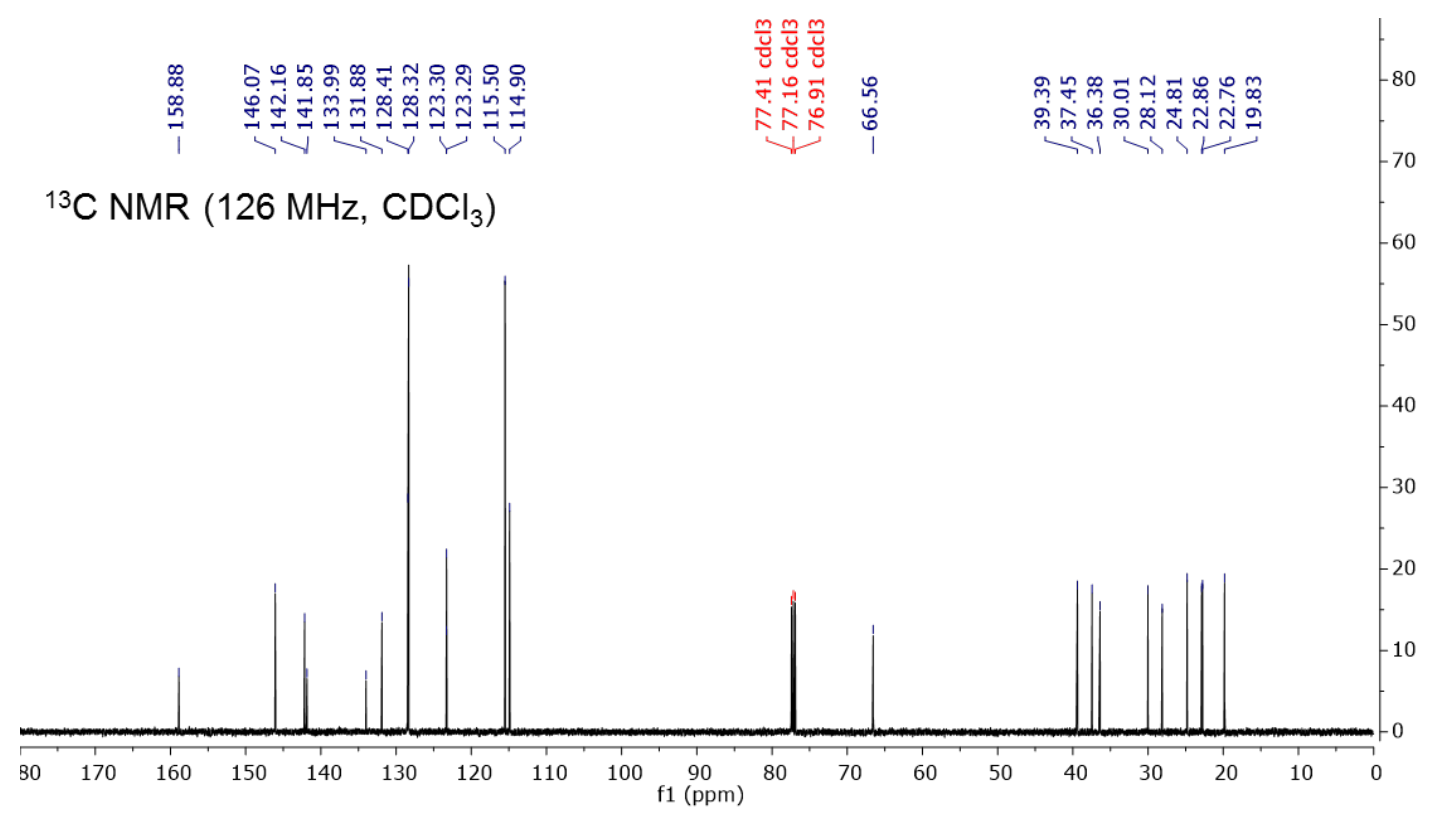

Figure S16. ${ }^{13} \mathrm{C}$ NMR spectrum $\left(\mathrm{CDCl}_{3}, 126 \mathrm{MHz}, 298 \mathrm{~K}\right)$ of R-DAPB.

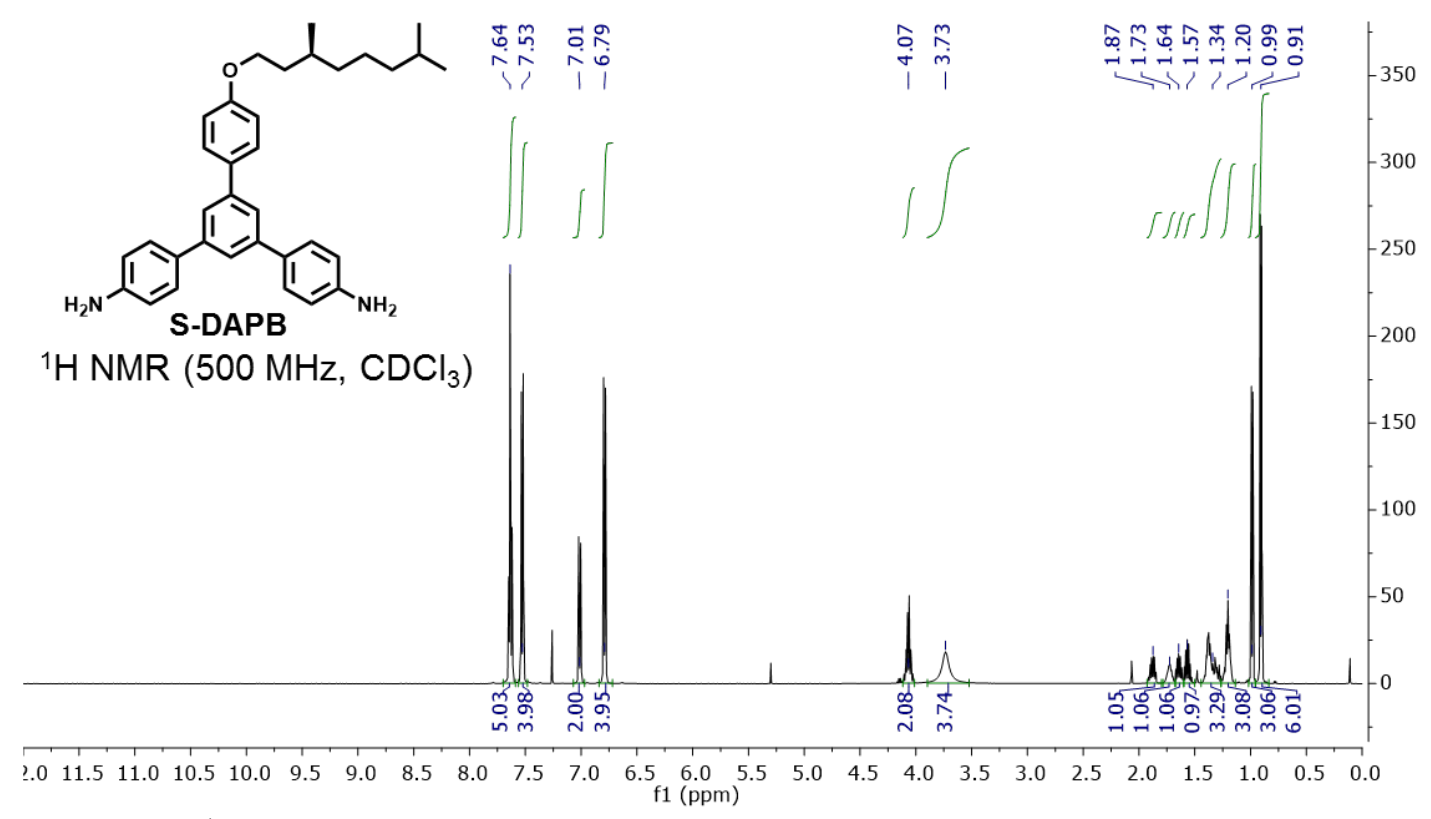

Figure S17. ${ }^{1} \mathrm{H}$ NMR spectrum $\left(\mathrm{CDCl}_{3}, 500 \mathrm{MHz}, 298 \mathrm{~K}\right)$ of S-DAPB. 


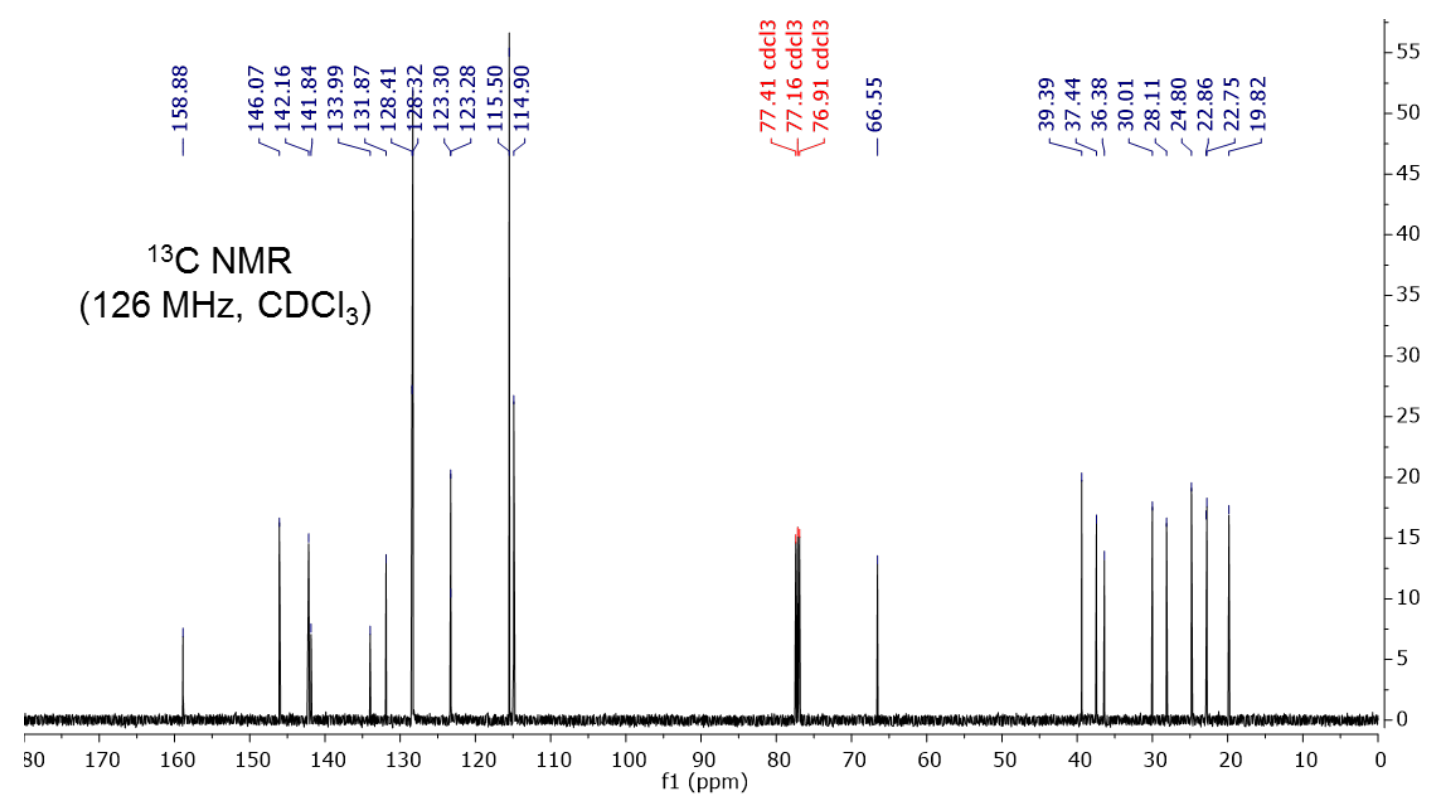

Figure S18. ${ }^{13} \mathrm{C}$ NMR spectrum $\left(\mathrm{CDCl}_{3}, 126 \mathrm{MHz}, 298 \mathrm{~K}\right)$ of S-DAPB. 


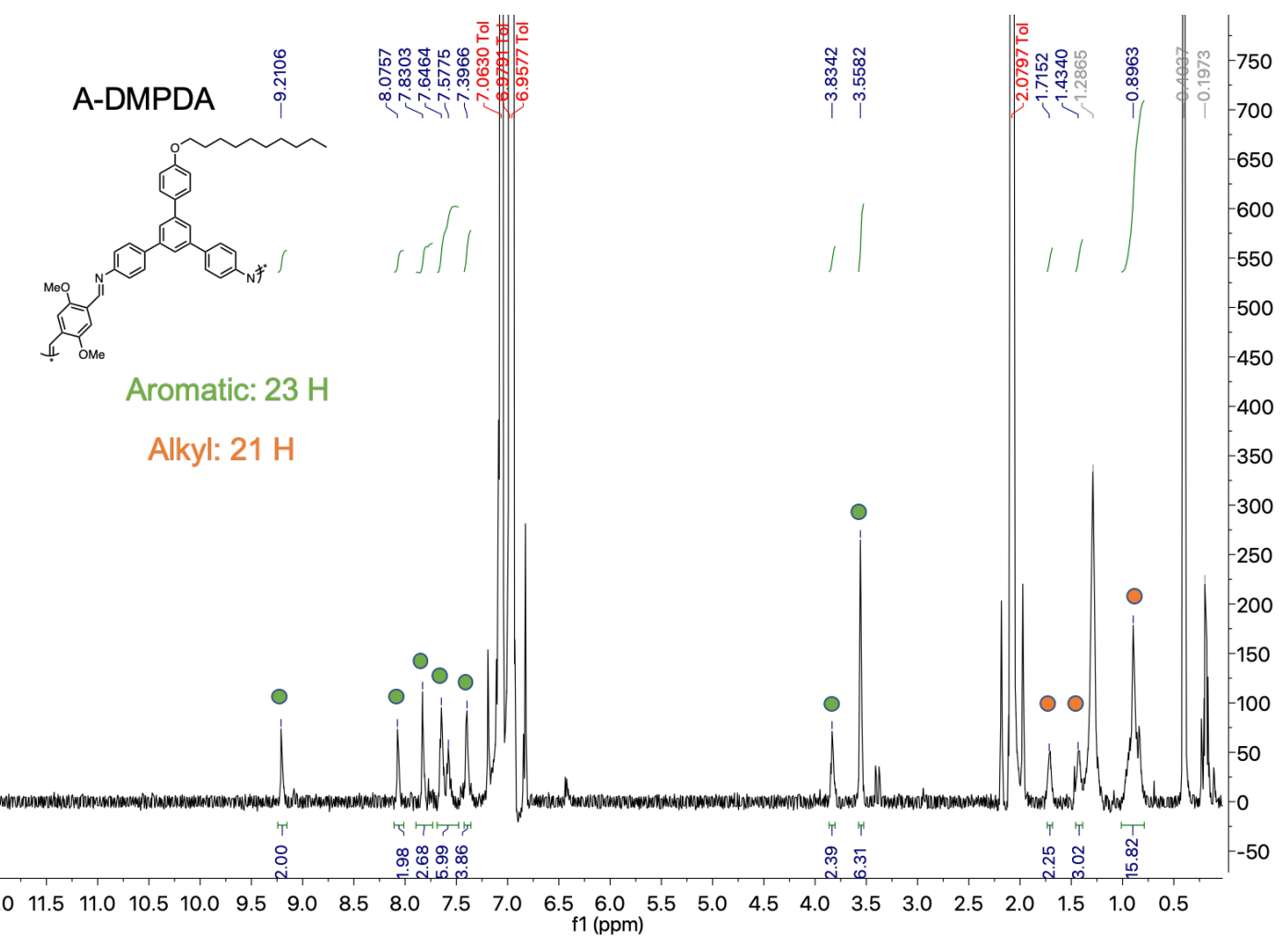

Figure S19. ${ }^{1} \mathrm{H}$ NMR spectrum (Toluene- $\mathrm{d}_{8}, 600 \mathrm{MHz}, 80{ }^{\circ} \mathrm{C}$ ) of A-DMPDA Macrocycle.

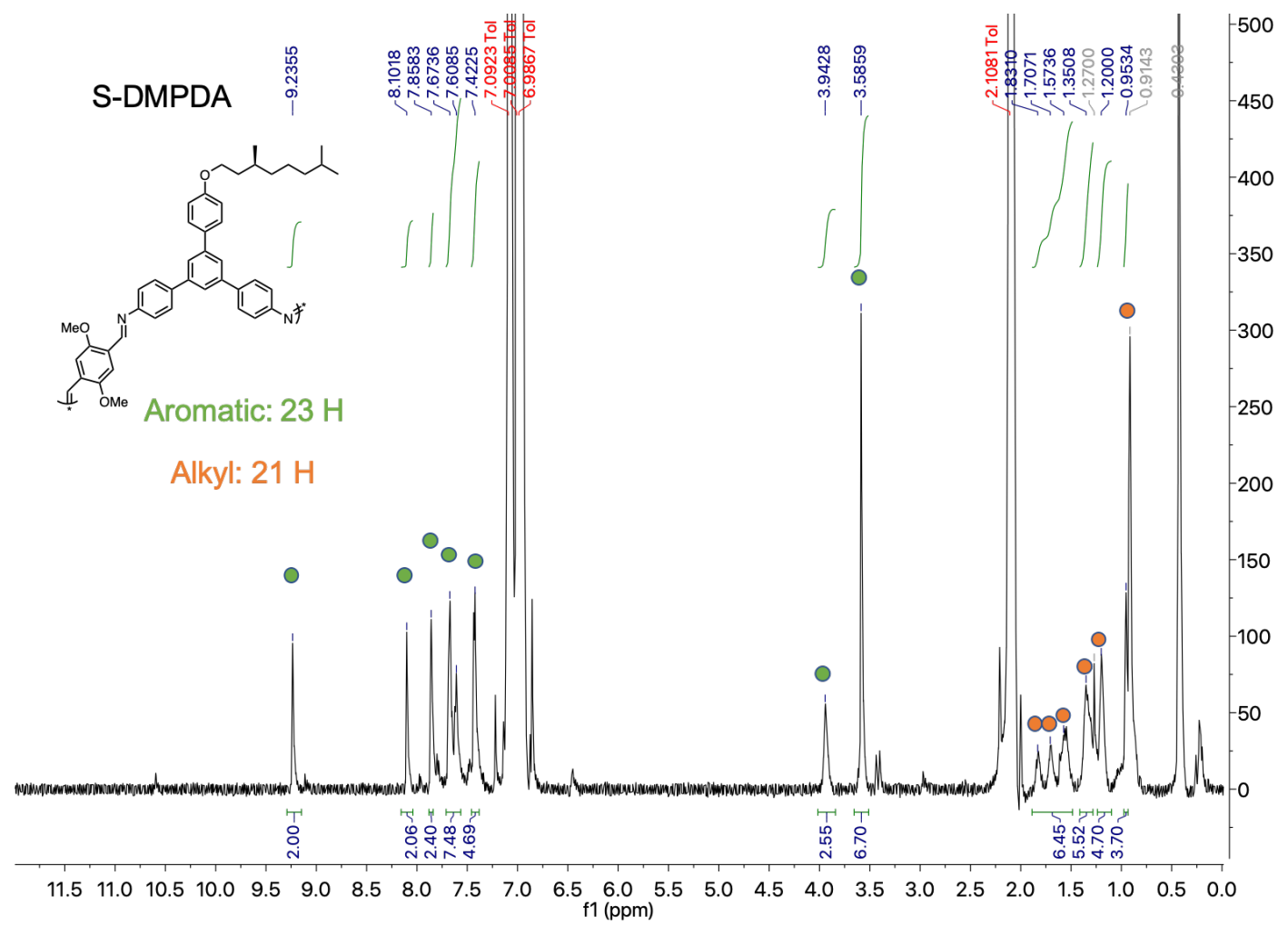

Figure S20. ${ }^{1} \mathrm{H}$ NMR spectrum (Toluene-d $8,600 \mathrm{MHz}, 80{ }^{\circ} \mathrm{C}$ ) of S-DMPDA Macrocycle. 


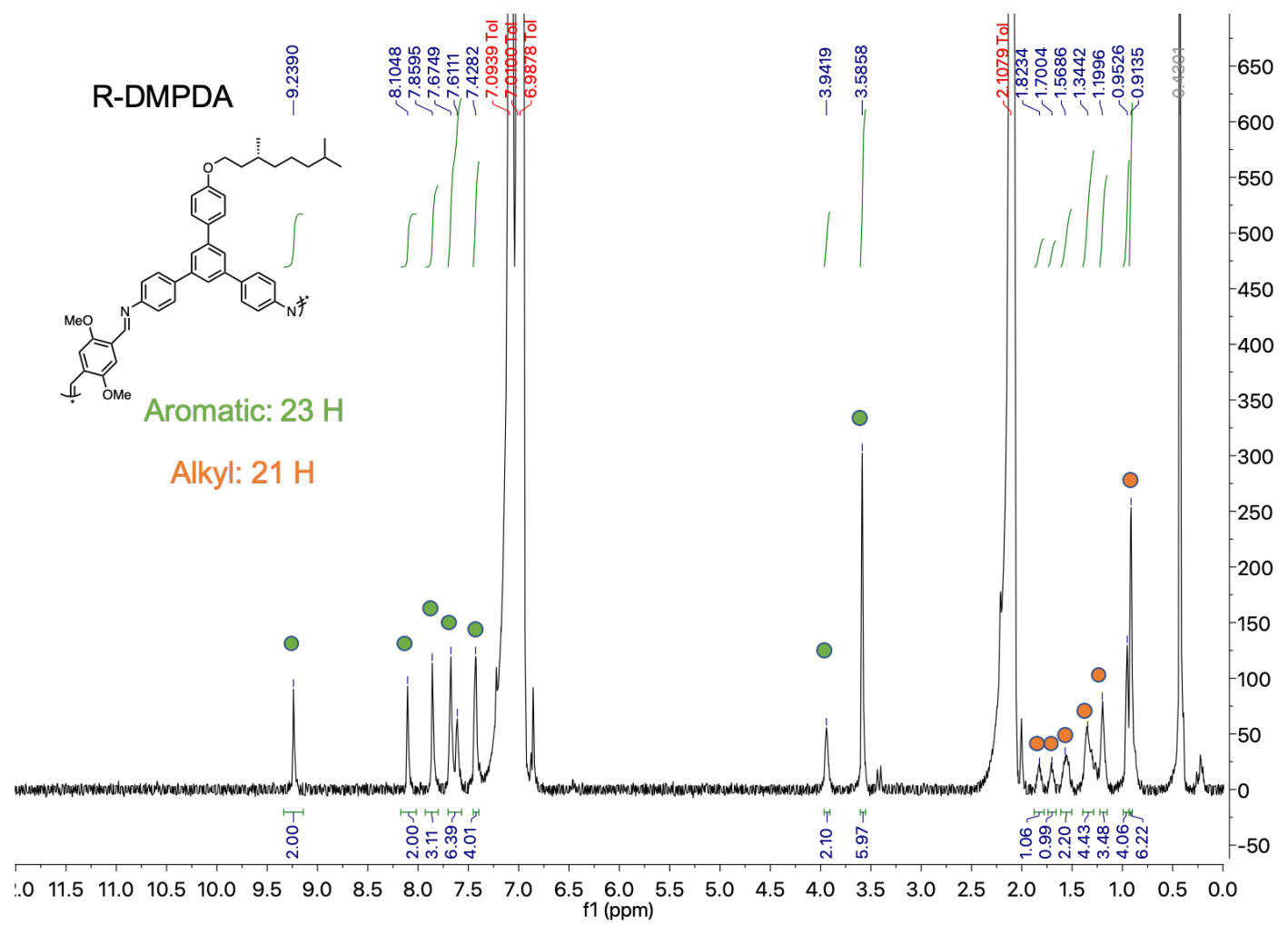

Figure S21. ${ }^{1} \mathrm{H}$ NMR spectrum (Toluene- $\mathrm{d}_{8}, 600 \mathrm{MHz}, 80{ }^{\circ} \mathrm{C}$ ) of R-DMPDA Macrocycle.

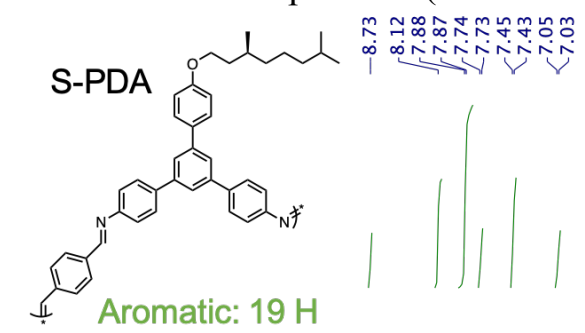

Alkyl: 21 H

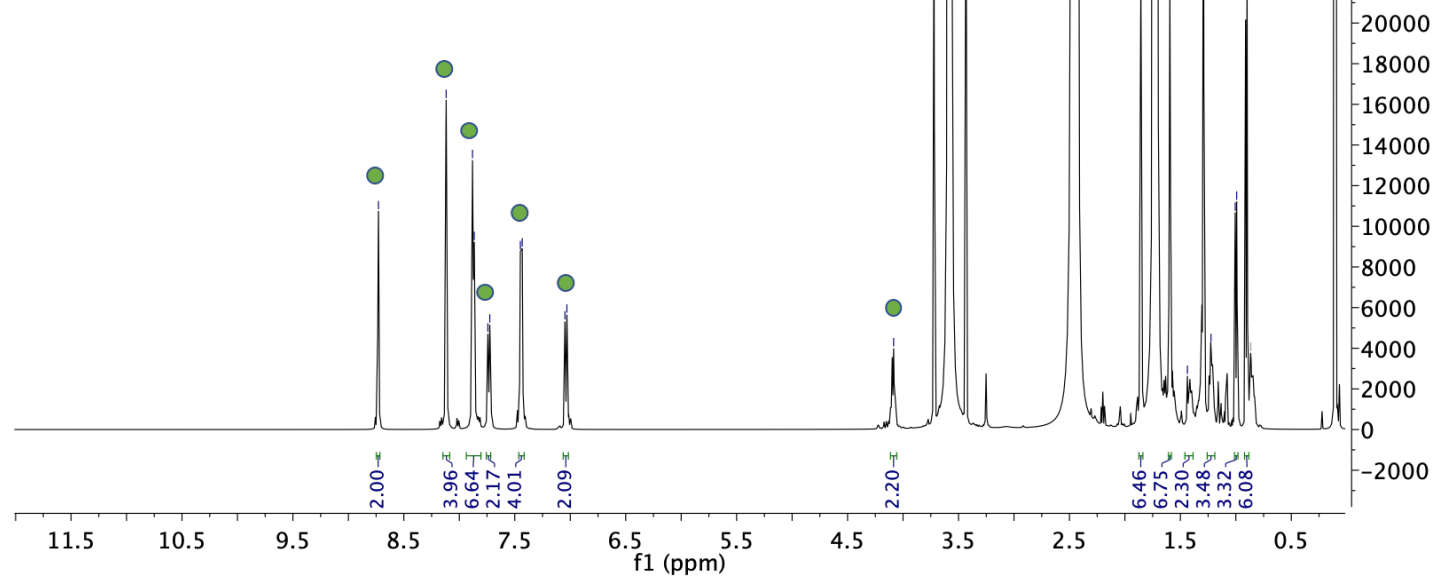

Figure S22. ${ }^{1} \mathrm{H}$ NMR spectrum $\left(\mathrm{THF}-\mathrm{d}_{8}, 500 \mathrm{MHz}, 25^{\circ} \mathrm{C}\right)$ of S-PDA Macrocycle. 


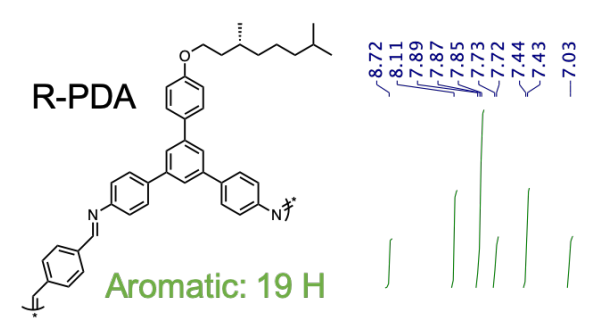

Alkyl: $21 \mathrm{H}$

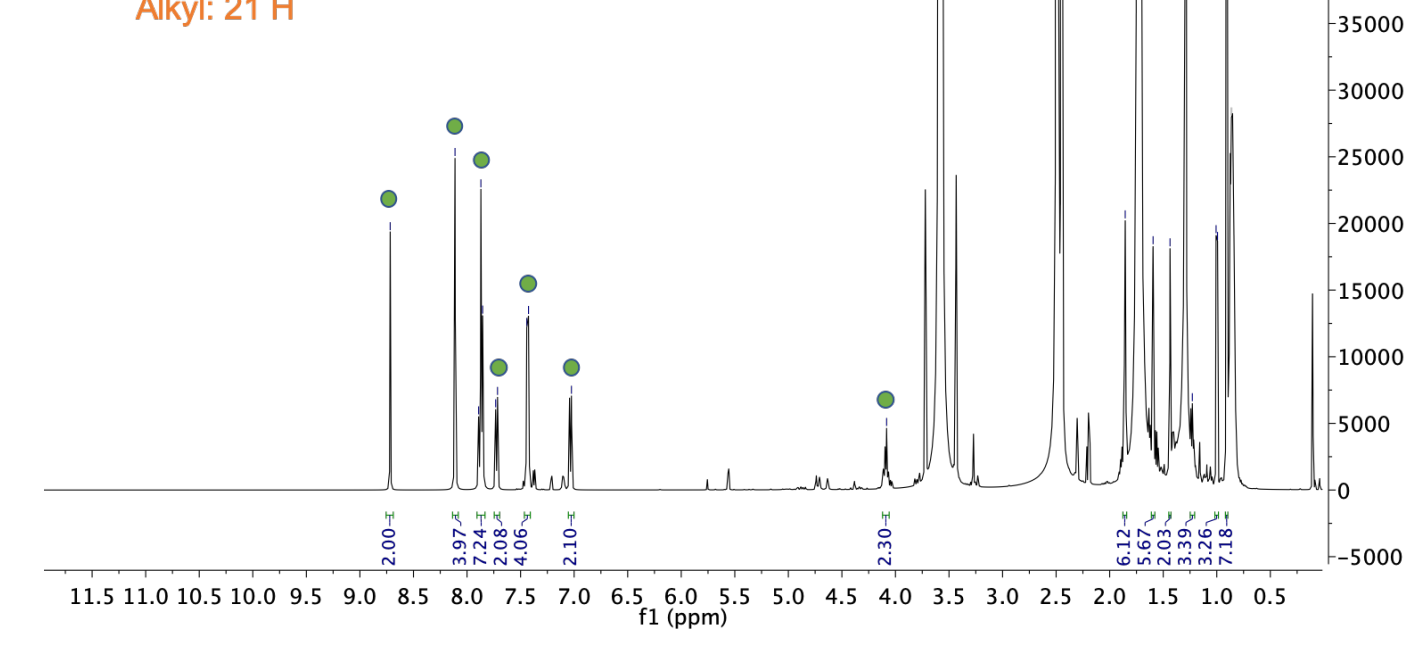

Figure S23. ${ }^{1} \mathrm{H}$ NMR spectrum $\left(\mathrm{THF}-\mathrm{d}_{8}, 500 \mathrm{MHz}, 25^{\circ} \mathrm{C}\right)$ of R-PDA Macrocycle. 


\section{E. References}

(1) Chavez, A. D.; Evans, A. M.; Flanders, N. C.; Bisbey, R. P.; Vitaku, E.; Chen, L. X.; Dichtel, W. R. Equilibration of Imine-Linked Polymers to Hexagonal Macrocycles Driven by Self-Assembly. Chem. Eur. J. 2018, 24, 3989-3993.

(2) Ślęczkowski, M. L.; Meijer, E. W.; Palmans, A. R. A. Cooperative Folding of Linear Poly(Dimethyl Siloxane)s via Supramolecular Interactions. Macromol. Rapid Commun. 2017, 38, 1700566.

(3) Markvoort, A. J.; ten Eikelder, H. M. M.; Hilbers, P. A. J.; de Greef, T. F. A.; Meijer, E. W. Theoretical Models of Nonlinear Effects in Two-Component Cooperative Supramolecular Copolymerizations. Nat. Commun. 2011, 2, 509.

(4) ten Eikelder, H. M. M.; Markvoort, A. J.; de Greef, T. F. A.; Hilbers, P. A. J. An Equilibrium Model for Chiral Amplification in Supramolecular Polymers. J. Phys. Chem. B 2012, 116, 5291-5301.

(5) Frisch, M. J.; Trucks, G. W.; Schlegel, H. B.; Scuseria, G. E.; Robb, A.; Cheeseman, J. R.; Scalmani, G.; Barone, V.; Petersson, G. A.; Nakatsuji, H.; et al. Gaussian 09, Revision A.01. Gaussian, Inc.: Wallingford, CT 2016.

(6) Stein, T.; Kronik, L.; Baer, R. Reliable Prediction of Charge Transfer Excitations in Molecular Complexes Using Time-Dependent Density Functional Theory. J. Am. Chem. Soc. 2009, 131, 2818-2820.

(7) Körzdörfer, T.; Bredas, J.-L. Organic Electronic Materials: Recent Advances in the DFT Description of the Ground and Excited States Using Tuned Range-Separated Hybrid Functionals. Acc. Chem. Res. 2014, 47, 3284-3291 